\title{
A foundational observation method for studying design situations
}

\author{
Cash, Philip; Hicks, Ben; Culley, Steve; Adlam, Tim
}

Published in:

Journal of Engineering Design

Link to article, DOI:

10.1080/09544828.2015.1020418

Publication date:

2015

Document Version

Peer reviewed version

Link back to DTU Orbit

Citation (APA):

Cash, P., Hicks, B., Culley, S., \& Adlam, T. (2015). A foundational observation method for studying design situations. Journal of Engineering Design, 26(7-9), 187-219. https://doi.org/10.1080/09544828.2015.1020418

\section{General rights}

Copyright and moral rights for the publications made accessible in the public portal are retained by the authors and/or other copyright owners and it is a condition of accessing publications that users recognise and abide by the legal requirements associated with these rights.

- Users may download and print one copy of any publication from the public portal for the purpose of private study or research.

- You may not further distribute the material or use it for any profit-making activity or commercial gain

- You may freely distribute the URL identifying the publication in the public portal

If you believe that this document breaches copyright please contact us providing details, and we will remove access to the work immediately and investigate your claim. 


\section{A foundational observation method for studying design situations}

Philip J. Cash ${ }^{1}$, Ben J. Hicks², Steve J. Culley ${ }^{3}$, Tim D. Adlam ${ }^{3}$

${ }^{1}$ Departement of Management Engineering, DTU, Denmark

${ }^{2}$ Department of Mechanical Engineering, University of Bristol, Bristol, UK

${ }^{3}$ Department of Mechanical Engineering, University of Bath, Bath, UK

*Corresponding author

To cite this article: Philip Cash, Ben Hicks, Steve Culley \& Tim Adlam (2015): A foundational observation method for studying design situations, Journal of Engineering Design, DOI: 10.1080/09544828.2015.1020418

To link to this article: http://dx.doi.org/10.1080/09544828.2015.1020418

Journal of Engineering Design

Department Of Management Engineering,

Technology Innovation Management

Technical University of Denmark

DK-2800 Lyngby, Denmark

Tel: +45 45254550

pcas@dtu.dk 


\section{A foundational observation method for studying design situations}

Observational studies of designers play an important role in engineering design research yet there is currently no accepted standard approach for comparing, combining or contrasting studies. Consequentially, reuse, reanalysis, replication, and aggregation of data are limited and the potential impact of individual studies is severely constrained. This paper begins to address this issue by introducing and developing a foundational method for observational design research to improve replicability, reuse, and overall comparability of empirical studies. A three-step foundational method is proposed that covers capture, coding, and analysis. The capture step defines overall and situational context as well as multiple capture streams, generating a broad dataset that can be examined from multiple perspectives. The coding step employs a multi-level approach that seeks to minimise workload whilst describing both detailed and high level information. The analysis step builds on the multilevel approach to provide for a flexible yet standardised examination of the dataset. The overall approach is introduced theoretically and illustrated using a comparison of an industrial study and an experimental study. Finally, it is argued that the proposed method promotes rigour, reliability, and standardisation; and could provide one means for improving comparison and aggregation, ultimately increasing impact in academia and practice.

\section{Introduction}

This paper develops a foundational method for observational design research with the aim to support the replication, reuse, and comparability of empirical design studies.

Design practice, and design activity specifically, have formed key foci in the design research domain (Cross 2007; Finger and Dixon 1989a; 1989b; Horvath 2004). Core to investigating these areas are observational approaches (Lethbridge, Sim, and Singer 2005), defined here as any approach directly recording the phenomena under study. These approaches aim to provide rigorous and robust characterisation of their subject. In the case of design this includes the practitioner, the process, the artefact, the environment, and wider context.

Observational approaches support theory building (Eisenhardt 1989; Briggs 2006), validation of experimental work (Bolton and Ockenfels 2008), and research impact (Glasgow and Emmons 2007). Fundamental to this role is the ability to bring multiple studies to bear on a single subject, triangulating results, accumulating significant samples, and varied complementary perspectives (Adelman 1991; Seale and Silverman 1997). Thus, it is critical that methods, data, and results can be compared, reused, and built upon. However, in 
design research there are currently no accepted standard approaches, frustrating such comparisons. For example, contrast Veldman and Alblas (2012) who systematically describe their cases, and Balogun (2006) who uses significantly different case descriptions. The lack of common structure or baseline means that despite similarities these studies are difficult to systematically compare.

There are two possible approaches to developing this basis for comparison. The first uses multiple identical studies, while the second aggregates multiple distinct, but related, studies. In both, standardised capture and analyse procedures can be used to support comparison. The first approach is well understood and thus this paper focuses on providing pragmatic support for aggregating studies. This has been directly inspired by Flay et al. (2005) who describe the positive impact of overlapping standards for methods and metrics in prevention research; and Brennan et al. (2011) and Kitchenham et al. (2002) who respectively propose methodological standards in policy research and software engineering.

The paper first explores the scope of existing approaches (Section 2). The foundational method is then proposed and illustrated via the comparison of an industrial and experimental case (Sections $3-7$ ). Finally implications for design research are distilled (Section 8).

\section{Background}

This section explores current issues and observational approaches in order to develop a foundation for the proposed method.

\subsection{Current Issues}

An extensive review of design research literature previously undertaken by the authors established six core issues (Cash 2012). These are listed alongside supporting references in Table 1.

Table 1: Core issues affecting observational research

\begin{tabular}{|l|l|l|}
\hline $\mathbf{N}^{\mathbf{0}}$ & Issue & Supporting reference \\
\hline 1 & Linking to theory & (Blessing and Chakrabarti 2009) \\
\hline 2 & Effective contextualisation & (Adelman 1991) \\
\hline 3 & Clear characterisation of the whole system & (Kitchenham et al. 2002) \\
\hline 4 & Definition and reporting of the method & (Dyba and Dingsoyr 2008) \\
\hline 5 & Mitigation of bias & (Kitchenham et al. 2002) \\
\hline 6 & The lack of validation, replication, and critical analysis & (Dyba and Dingsoyr 2008) \\
\hline
\end{tabular}


When considering observational research, the six core issues generally manifest themselves as a number of practical problems. Table 2 provides further description of these problems, which are also discussed by the authors highlighted in Table 1. This explicitly focuses on problems related to method. In particular, characterisation of the system (Issue 3 ) is decomposed into sampling and research design, while mitigating bias (Issue 5) is split into reflexivity and data analysis.

Table 2: Specific methodological problems

\begin{tabular}{|l|l|}
\hline Problem & Description \\
\hline Linking to theory & Effectively fitting the work into the wider field and associated theory \\
\hline Describing context & Characterizing context to support generalization and links to theory \\
\hline Sampling design & Avoiding sampling bias to effectively represent the population \\
\hline Research design & Designing and reporting the research to support replication and validation \\
\hline Data collection & Avoiding bias and information overload whilst giving a rich dataset \\
\hline Reflexivity & $\begin{array}{l}\text { Managing the research/participant relationship to minimize bias and } \\
\text { experimental effects }\end{array}$ \\
\hline Data analysis & Minimizing bias while giving results that can be effectively interrogated \\
\hline Value of findings & Defining the validity, nature and role of the findings in the wider context \\
\hline
\end{tabular}

\subsection{Observational Approaches - Advantages and Limitations}

There are many approaches to the characterisation of design practice (Lethbridge, Sim, and Singer 2005). The most common of which are summarised in Table 3, with references provided to exemplify each approach.

Table 3: Observational approaches for characterising practice

\begin{tabular}{|l|l|}
\hline Approach & Description \\
\hline Work diary & $\begin{array}{l}\text { Participants report events either concurrently or reflectively e.g. Wild et al. } \\
(2010)\end{array}$ \\
\hline Work sampling & Participants report events as prompted e.g. Robinson (2010) \\
\hline $\begin{array}{l}\text { Applied } \\
\text { ethnography }\end{array}$ & $\begin{array}{l}\text { A combination of observation, interviews, and other studies e.g. Ball and } \\
\text { Ormerod (2000) }\end{array}$ \\
\hline Autoethnography & Focusing ethnographic techniques on the self e.g. Cunningham (2005) \\
\hline Shadowing & $\begin{array}{l}\text { Researchers follow the participant recording their activity e.g. Bergstrom et al. } \\
\text { (2008) }\end{array}$ \\
\hline $\begin{array}{l}\text { Instrumented } \\
\text { systems }\end{array}$ & $\begin{array}{l}\text { Participant activity is automatically record via computer e.g. Lethbridge et al. } \\
\text { (2005) }\end{array}$ \\
\hline Fly on the wall & Participants record themselves using video or audio e.g. Cooper et al. (2002) \\
\hline
\end{tabular}

Through consideration of the core issues and the specific methodological problems the advantages and limitations of these approaches can be assessed. This is summarised in Table 4. The highlighted limitations all affect theory building (Issue 1) and system characterisation (Issue 3). Thus these are not listed to avoid repetition. Applied ethnography and autoethnography are included here because they have 
been specifically developed to be compatible with a realist approach making them suitable for this comparison.

Based on this assessment it is possible to imagine a combination of approaches that could reduce, or even eliminate, many of the limitations while maximising the collective advantages. There are two possible approaches for realising this combinatorial concept. The first is standardised selection, which seeks comparability and traceability by providing a common framework for choosing research, data capture, and analysis methods. This would use a weighting of advantages and limitations, derived from the fundamental research questions being asked and the specific situation under investigation to guide optimal selection. While a standard selection approach is feasible it is the second approach - a foundational method that is considered here. A foundational method achieves comparability by systematically defining standard study elements to provide a common baseline.

Table 4: Advantages and limitations of current approaches

\begin{tabular}{|c|c|c|c|}
\hline Approach & Advantages & Limitations & $\begin{array}{l}\text { Relation to the core } \\
\text { issues }\end{array}$ \\
\hline Work diary & $\begin{array}{l}\text { Provides insight over a long } \\
\text { period without incurring } \\
\text { significant demands on the } \\
\text { researcher }\end{array}$ & $\begin{array}{l}\text { Difficult to account for } \\
\text { bias introduced through } \\
\text { self reporting or } \\
\text { contextual information }\end{array}$ & $\begin{array}{l}\text { Difficult to account for } \\
\text { bias (Issue 5), validate, } \\
\text { replicate or generalise } \\
\text { (Issue 6) }\end{array}$ \\
\hline Work sampling & $\begin{array}{l}\text { Generates large amounts } \\
\text { of data without incurring } \\
\text { significant demands on the } \\
\text { researcher }\end{array}$ & $\begin{array}{l}\text { Difficult to account for } \\
\text { bias introduced through } \\
\text { self reporting or } \\
\text { contextual information }\end{array}$ & $\begin{array}{l}\text { Difficult to account for } \\
\text { bias (Issue 5), can lack } \\
\text { wider characterisation } \\
\text { of the system (Issue 3) }\end{array}$ \\
\hline $\begin{array}{l}\text { Applied } \\
\text { ethnography }\end{array}$ & $\begin{array}{l}\text { Provides insight into } \\
\text { practice and is not tied to a } \\
\text { constructivist paradigm }\end{array}$ & $\begin{array}{l}\text { Difficult to effectively } \\
\text { report the full dataset } \\
\text { and can be affected by } \\
\text { bias }\end{array}$ & $\begin{array}{l}\text { Difficult to account for } \\
\text { bias (Issue 5), difficult } \\
\text { to validate, replicate or } \\
\text { generalise (Issue 6) }\end{array}$ \\
\hline Autoethnography & $\begin{array}{l}\text { Provides unique insight by } \\
\text { making the investigator } \\
\text { the focus of the study }\end{array}$ & $\begin{array}{l}\text { Difficult to account for } \\
\text { bias, typically of a } \\
\text { limited sample size and } \\
\text { scope }\end{array}$ & $\begin{array}{l}\text { As above but can also } \\
\text { be linked to Issue } 3 \text { due } \\
\text { to the limited } \\
\text { perspective }\end{array}$ \\
\hline Shadowing & $\begin{array}{l}\text { Can cover a wide range of } \\
\text { attributes and requires no } \\
\text { additional equipment }\end{array}$ & $\begin{array}{l}\text { Difficult to account for } \\
\text { bias and typically of a } \\
\text { limited sample size }\end{array}$ & $\begin{array}{l}\text { Issues } 5 \text { and } 6 \text { play a } \\
\text { large role in studies of } \\
\text { this type }\end{array}$ \\
\hline $\begin{array}{l}\text { Instrumented } \\
\text { systems }\end{array}$ & $\begin{array}{l}\text { Can provide accurate long } \\
\text { term information on } \\
\text { specific factors such as } \\
\text { patterns of computer use }\end{array}$ & $\begin{array}{l}\text { Difficult to address } \\
\text { contextual information } \\
\text { or effectively } \\
\text { characterise the whole } \\
\text { system }\end{array}$ & $\begin{array}{l}\text { Difficult to effectively } \\
\text { contextualise system } \\
\text { use (Issue } 2 \text { ) and its } \\
\text { relation to other work } \\
\text { (Issue } 1 \text { ) }\end{array}$ \\
\hline Fly on the wall & $\begin{array}{l}\text { Unobtrusive and allows } \\
\text { participants to acclimatise } \\
\text { quickly with little } \\
\text { disruption }\end{array}$ & $\begin{array}{l}\text { Difficult to account for } \\
\text { bias introduced through } \\
\text { self reporting and } \\
\text { limited scope }\end{array}$ & $\begin{array}{l}\text { Issues } 5 \text { and } 6 \text { play a } \\
\text { large role in studies of } \\
\text { this type }\end{array}$ \\
\hline
\end{tabular}




\section{Developing the Method}

Defining the philosophical and theoretical assumptions underpinning the foundational method is critical to understanding its scope and applicability (Robson 2002). A critical realist perspective was selected for three main reasons. First, critical realism and post-positivism (closely related) dominate design research, allowing easier integration with current design research practice. Second, critical realism conceptually decomposes the system under investigation into core elements - input action, output, mechanisms, and context. Third, this decomposition can be used to define discreet situations. These two features support flexibility whist retaining commonality and are illustrated with respect to the foundational method in Figure 1. Key terms are defined as follows:

Figure 1: A critical realist perspective with respect to the foundational method Overall design process

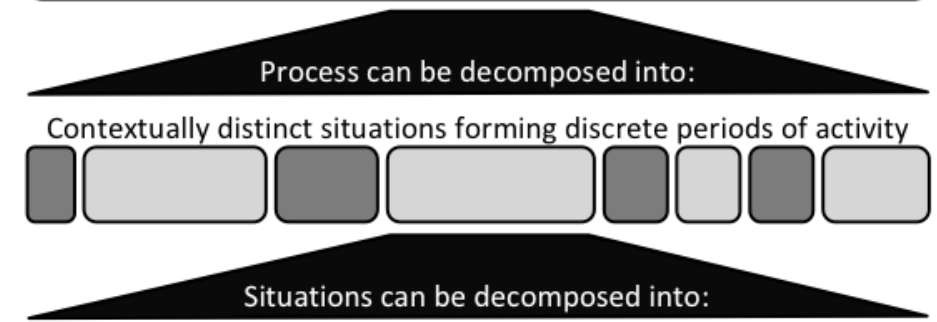

Systems characterised by an input action and output produced through a number of mechanisms in a particular context

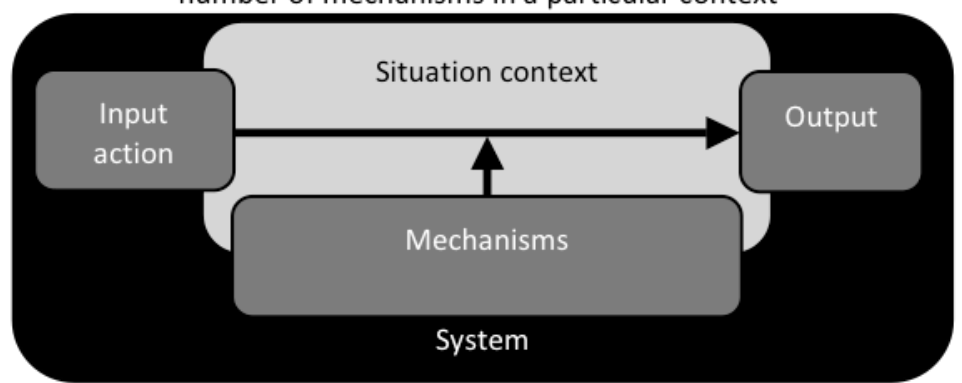

Situation: Contextually discreet periods of activity defined by stage of the design process, focus, general purpose, and setting.

Overall context: The world in which situations exist, defined by the overall process, company composition, and other generic elements linking all situations in a study.

Situational context: The general features of the activity (interactions, overall focus, and process stage) in a situation. The circumstances in which a situation takes place. 
Input action: The impetus for change that results in an activity being undertaken e.g. a decision and move to a meeting room with the intent of brainstorming could be one input action leading to an ideation situation.

Mechanisms: The processes and variables through which the final output is achieved e.g. the cognitive processes of the designer, or idea iteration in a discussion.

Output: The measurable resultant features of a situation e.g. the number or quality of the ideas produced.

\subsection{Standardisation Versus Flexibility}

Two theoretical needs underpin the foundational method: identifying the elements necessary for robust comparison, and balancing prescription and flexibility. These are key to supporting effective standardisation without stifling new research approaches. Figure 2 depicts an idealised comparison where the elements in each situation are described in a standard way. This allows for direct comparison and triangulation without significant additional work.

Figure 2: An idealised comparison using a situation-based framework

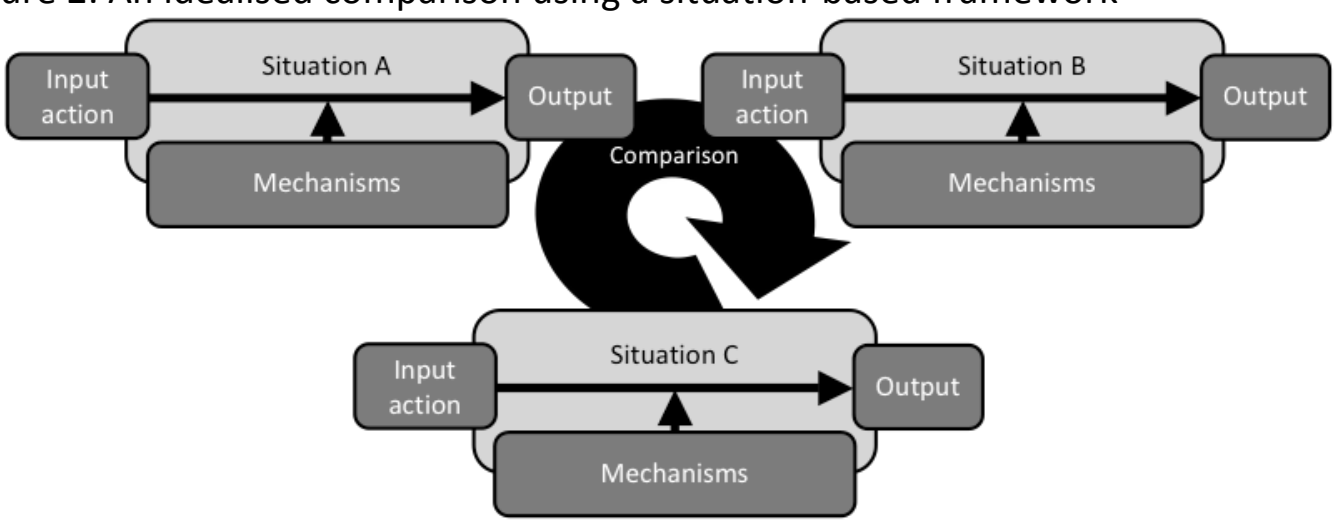

Comparing systems in this way allows deeper insight into the mechanisms, which underpins effective theory building: "If we understand nothing of the causal mechanisms, then we can only achieve a given outcome by accident at first and by rote thereafter" (Briggs 2006, 581).

Figure 3 illustrates how standardisation and flexibility can be balanced. Standard elements include common methods, metrics, selection systems or training regimes. With respect to the foundational method, standardisation is primarily associated with partial prescription of certain methodological features. Conversely, flexibility describes research specific elements including unique selection regimes, new 
metrics or new methods. These are brought together with the aim of maintaining scientific rigour. Mays and Pope (1995) state that the basic strategy for achieving rigour is: "systematic and self conscious research design, data collection, interpretation, and communication." Thus the ideal case would be standardisation without reduced flexibility or rigour. Here, Figure 3 shows a case where additional prescribed elements give a standard baseline without limiting the scope of the approach, even including grounded 'high flexibility' approaches. Although additional work is required to add the standard elements they do not constrain the construction of new methods, metrics or hypotheses. Hence this forms a standardised foundation upon which a range of methods or datasets can be built and compared.

Figure 3: The idealised role of a foundational method

Typical research method

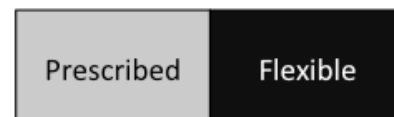

High flexibility

High standardisation
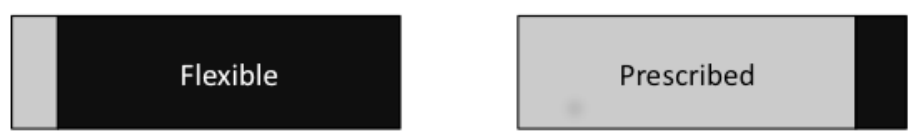

Typical method with additional

standardised elements

Additional

prescribed

\subsection{Creating a New Method}

In order to address the issues and the needs of standardisation/flexibility we take inspiration from key elements of existing approaches, including, Robinson (2010), McAlpine et al. (2011), and Wasiak et al. (2010). Specifically, the combination of capture sources described by McAlpine et al., the multiple perspectives on engineering work used by Wasiak et al., and the multi-level analysis proposed by Robinson. Further, we build on extensive prototyping of the approach.

\subsection{Theoretical Framework and Terminology}

Several aspects of the framework outlined in Figure 1 require further discussion. In particular, overall context has been developed from the work of Prudhomme et al. 
(2007) and Visser (2009). Prudhomme et al. define a situation as including both the design process and other non-design activities. Visser defines a situation with respect to the process, designer, and artefact. Both of these conceptions are different from the situation as outlined in Figure 1, hence we have adopted the term 'overall context' to avoid confusion. Further, neither approach is suitable for linking all levels of the framework (Figure 1). As such, they have been combined and expanded in the foundational method.

There are three areas to consider in balancing standardisation and flexibility. First, decomposing the observation period into discreet situations defined by common contextual factors allows for systematic description of a situation without constraining the scope of investigation. Further, by defining the granularity of the description it is possible to describe both the overall study and fleeting situations within it using the same spectrum of standardised comparison. This allows for studies at different levels to be compared in a common reference frame. Second, the standard conceptualisation of the situation (input action, output, mechanisms, and situation: Figure 1) gives a common core upon which to build comparability. Finally, activity can be used to form the basis for assessing the various situations. This is based on Activity Theory summarised by Bedny and Harris (2005): "Activity is a goaldirected system, where cognition, behaviour, and motivation are integrated and organised by a mechanism of self-regulation toward achieving a conscious goal." (p.130)

Operationalizing these concepts, the foundational method uses an integrated threestage approach: capture (Section 4) - characterising the overall context, and providing the data for situation identification and investigation; coding (Section 5) characterising the situational context, and providing a basis for detailed comparison; and analysis (Section 6) - exploring the situation with respect to the overall, and situational context. Although combining capture, coding, and analysis in one method is not in itself novel, each stage draws on unique elements that contribute to a more effective overarching method. This allows for research flexibility whilst maintaining standardisation and addressing the identified methodological problems. 


\subsection{The Foundational Method and Comparison Study}

To illustrate each of these stages a comparison study is detailed in Section 7. Figure 4 shows the methods generic steps and links these to the specific work undertaken during the comparison study. It also illustrates how each stage has both standard and flexible elements. It is envisaged that in many cases, standard elements such as the capture strategy will overlap substantially with the specific demands of a particular study.

Figure 4: General method (left), and an example of its application (right)

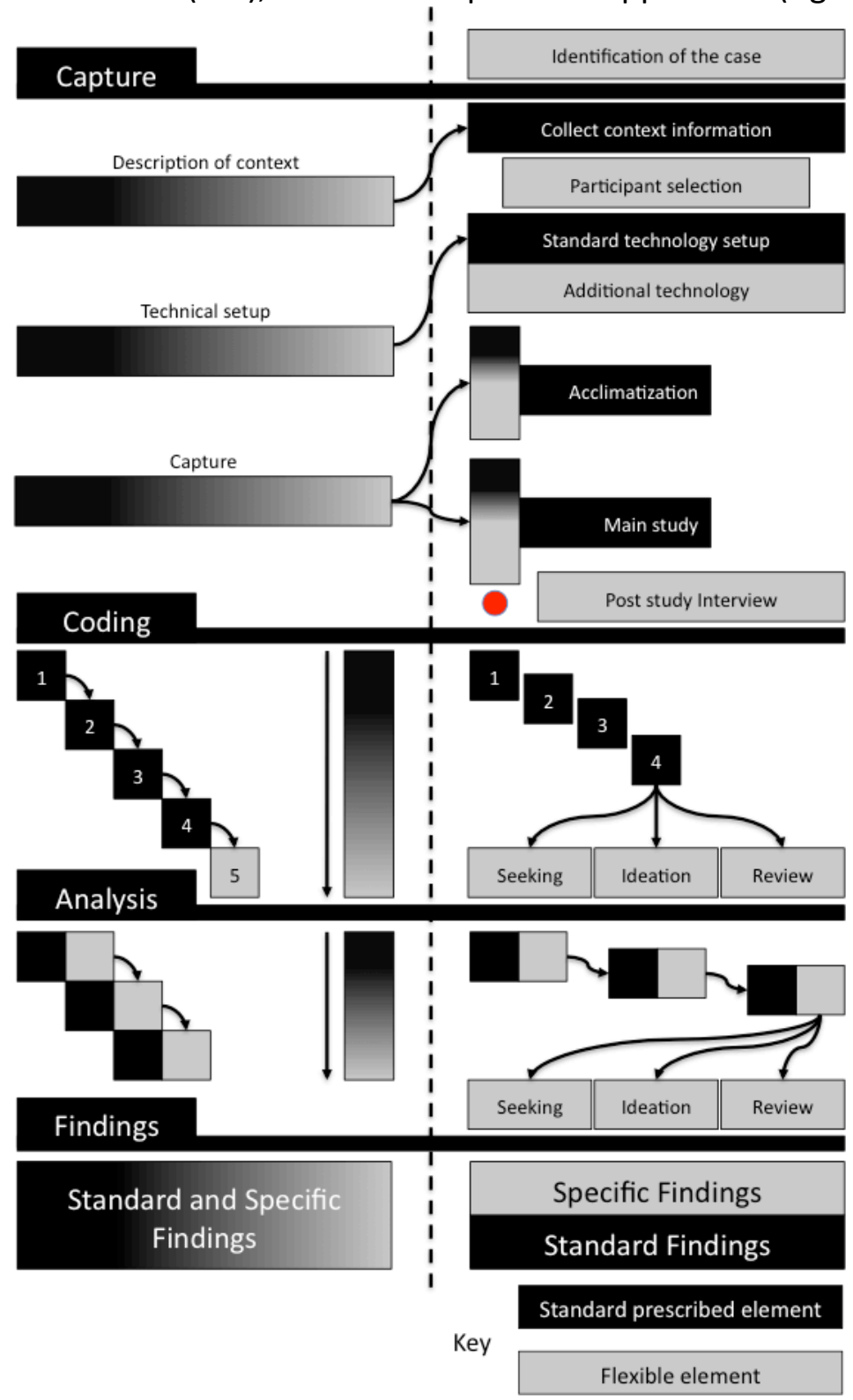




\section{Capture Strategy}

There are three major aspects of the capture strategy: description of overall context, technical setup, and data collection.

\subsection{Description of Overall Context}

Context underpins generalisability and external validity (Kitchenham 1996; McCandliss, Kalchman, and Bryant 2003), and plays a critical role in comparison, reuse, and uptake (Shavelson et al. 2003). Thus this section outlines standard overall contextual factors, although it is expected that additional hypothesis specific factors be recorded as necessary (Section 3).

While overall context is important there are no widely accepted classifications. Terms commonly associated with 'context' are: activity, organizational, cultural, social, and historical (Klein and Myers 1999; Malterud 2001; Wildemuth 1993). When comparing these terms, it is apparent that organizational and cultural are related. 'Cultural' covers aspects associated with the participant including national and developmental background (Janssen, Van de Vliert, and West 2004), and is commonly described via the cultural onion metaphor (Gallivan and Srite 2005). Conversely, 'organizational' is used to describe company culture and thus forms one specific layer of the larger cultural onion. Further, 'activity' has a different definition from that explained previously as part of Activity Theory, hence we subsequently use 'technical environment'. Considering each aspect from a company and participant perspective four main areas emerge: technical environment, social, cultural, and historical. Practically, overall contextual information can be record either pre or post study depending on the specific research focus. The 'context first' approach given in Figure 4 is for illustrative purposes only. The full list of overall contextual features and metrics for each aspect are listed in the appendix.

\subsubsection{Technical Environment}

The technical environment influences what activities the participant undertakes and their potential modes of action. As such, the participants' environment needs to be characterised in order to establish the technical and structural influences on activity. 
For example, a setting with only one meeting room and a densely populated openplan office might produce an abnormally large number of informal meetings that could be misinterpreted if not properly contextualised. With respect to the participant, the bulk of activity is likely to involve either their personal computer or logbook (McAlpine et al. 2006), dictating that the use of these systems/tools be recorded in a structured manner.

The standard features recorded in the foundational method are the technical layout and resources in the workspace: the physical distribution of the participant(s), other workers, and the overall layout of the working environment; the distribution of working time between the primary workspace and other areas e.g. the home or workshop; and the technical affordances of the space likely to affect activity e.g. the distribution of whiteboards and other equipment.

\subsubsection{Social}

The factors required for baselining a participant population are measured using socioeconomic status. This has a number of established variables that are used across fields (Adler and Ostrove 2006; Pickett and Pearl 2001). These variables aim to give insight into factors such as social norms (Levitt and List 2007), social status (Jakesch et al. 2011), independence, and interests (Shalley and Gilson 2004). The standard measures used for this are summarised in the appendix.

At the organisational level, there are also a number of comparative factors. Those associated with the social context of the organisation (i.e. affecting job complexity, demands, challenges, and autonomy (Shalley and Gilson 2004)) include: funding level, income source, market pressures, environmental factors, other monetary pressures, and the composition of the organisation's population.

\subsubsection{Cultural}

Cultural factors have two major aspects considered here, the national cultural background of the participant and the specific organisational culture. Petre (2004) highlights the effect of both these aspects on practitioner behaviour. With respect to national culture, cultural distance measures are well established (Shenkar 2001). 
These can be used to generally define the participant population (Kogut and Singh 1988; Dow and Ferencikova 2010), including elements such as collectivism/individualism and group homogeneity (Janssen, Van de Vliert, and West 2004; Shalley and Gilson 2004). These factors are operationalized by Hofstede et al. (2010).

With respect to organisational culture key factors include hierarchy, level of formality, level of socialising, and overall homogeneity (Guzzo and Dickson 1996; Stewart 2006). Factors specifically related to engineering design include: pride in quality of work, competitiveness, type of design work (Wild et al. 2005), organizational aims or areas of support (Janssen, Van de Vliert, and West 2004), and existing projects and practices (Lewis and Moultrie 2005). This is again operationalized using Hofstede et al.'s (2010) cultural measures for organisations.

\subsubsection{Historical}

Historical factors typically manifest indirectly via the current social or cultural context. As such, there is little to directly assess in this aspect. However, two relevant areas are annual turnover and market maturity. These play a confirmatory role, complementing the factors recorded in the social and cultural areas. In terms of the participant, the key historical factor is their previous experience and knowledge (Shalley and Gilson 2004; Jakesch et al. 2011).

Ultimately numerous variables affect the outcome of a study, however, those highlighted here form a core set of recognised variables necessary for defining a study and its population. Both in a general sense and in relation to engineering design specifically. These standard parts support generalisation without demanding deep research into contextualisation, which comprises a research area in its own right.

\subsection{Technical Setup}

The standard aspects of equipment selection and setup were based on the work of McAlpine et al. (2011) who assess a range of capture technologies against their level of coverage and data collection/analysis demands. Here, the use of multiple capture pathways allows for the wide variety of situations likely to be encountered in 
practice. This also partially mitigates recording limitations often imposed in an industry setting by providing a rich record of those periods where data capture is permitted.

The standard technical setup guides equipment distribution with respect to the generic aspects of engineering activity e.g. the workstation and logbook. However, the details of placement are strictly situational, being based on the participants' perception of their working practice (Section 4.1.1). Thus, this provides a standard foundation while research specific additions address the needs of within study validity and insight. To give an effective foundation for reuse and generalisation the standard setup is designed to capture the widest range of possible activities. Table 5 outlines these standard capture elements and how they overlap. This overlap is important for synchronisation, providing redundancy, and allowing triangulation during analysis (H. Robinson, Segal, and Sharp 2007; Seale 1999).

Table 5: Standard capture elements and relevant technical approaches

\begin{tabular}{|c|c|c|c|}
\hline Perspective & Approach & What it is recording & Further information \\
\hline Participant & $\begin{array}{l}\text { Synchronised } \\
\text { camera } 1\end{array}$ & $\begin{array}{l}\text { Front view of participant - high resolution, } \\
\text { synchronised with other cameras }\end{array}$ & \multirow{2}{*}{$\begin{array}{l}\text { www.panopto.com } \\
\text { and standard HD } \\
\text { web cameras } \\
\text { (Panopto 2012) }\end{array}$} \\
\hline Workspace & $\begin{array}{l}\text { Synchronised } \\
\text { camera } 2\end{array}$ & $\begin{array}{l}\text { Wide view of main workspace - audio and } \\
\text { video synchronised with other cameras }\end{array}$ & \\
\hline $\begin{array}{l}\text { Detail of PC } \\
\text { work }\end{array}$ & $\begin{array}{l}\text { Synchronised } \\
\text { screen capture }\end{array}$ & $\begin{array}{l}\text { Live screen recording - high resolution, } \\
\text { synchronised with cameras via e.g. } \\
\text { panopto }\end{array}$ & www.panopto.com \\
\hline $\begin{array}{l}\text { Overall PC } \\
\text { usage }\end{array}$ & $\begin{array}{l}\text { Long term data } \\
\text { logging }\end{array}$ & $\begin{array}{l}\text { Automatic recording of computer usage - } \\
\text { usage, documents and applications }\end{array}$ & $\begin{array}{l}\text { www.manictime.com } \\
\text { (ManicTime 2011) }\end{array}$ \\
\hline $\begin{array}{l}\text { Participant } \\
\text { view }\end{array}$ & Mobile camera & $\begin{array}{l}\text { Participants view of situations away from } \\
\text { the work station }\end{array}$ & $\begin{array}{l}\text { e.g. Looxcie head } \\
\text { mounted camera }\end{array}$ \\
\hline $\begin{array}{l}\text { Written } \\
\text { notes }\end{array}$ & $\begin{array}{l}\text { Recording of } \\
\text { logbook }\end{array}$ & $\begin{array}{l}\text { Participants notepad use and audio - } \\
\text { writing and audio playback of logbook }\end{array}$ & $\frac{\text { www.livescribe.com }}{\text { (LiveScribe 2011) }}$ \\
\hline $\begin{array}{l}\text { Participant } \\
\text { background }\end{array}$ & Work diary & $\begin{array}{l}\text { Participant records activities not otherwise } \\
\text { captured in structured form }\end{array}$ & $\begin{array}{l}\text { Questionnaire e.g. } \\
\text { Robinson (2010) }\end{array}$ \\
\hline
\end{tabular}

With respect to engineering work each aspect is covered by at least two complementary techniques, given in Table 6 . The engineering work activities are taken primarily from Hales (1987), Robinson (2010), and Austin et al. (2001). Key non-technical issues are those of privacy, ethics and confidentiality. Again, the standard capture setup has been designed to mitigate these concerns where possible through redundancy (Table 6). For example, long-term data logging allows a portion of the data to be anonymised on collection rather than after coding. Here, using overlapping, linked recording mechanisms (e.g. multiple synchronised 
cameras) allows the participant to manage the recording process simply and transparently.

Table 6: Summary of engineering activities and the associated approaches

\begin{tabular}{|c|c|c|}
\hline $\begin{array}{l}\text { Engineering } \\
\text { activities }\end{array}$ & Approaches & What is captured \\
\hline \multirow{2}{*}{$\begin{array}{l}\text { Collocated meetings } \\
\text { and collaboration }\end{array}$} & Recording of logbook & Meeting notes and audio of conversation \\
\hline & Mobile camera & Audio and video from the participants perspective \\
\hline \multirow{2}{*}{$\begin{array}{l}\text { Written } \\
\text { communication }\end{array}$} & Synch. screen capture & E-mail and other messaging activity via computer \\
\hline & Work diary & Other messaging activity \\
\hline \multirow{2}{*}{$\begin{array}{l}\text { Distributed } \\
\text { communication }\end{array}$} & Synch. cameras & Audio and visual of phone or computer use \\
\hline & Synch. screen capture & Computer based video conferencing \\
\hline \multirow{3}{*}{$\begin{array}{l}\text { Individual design } \\
\text { work }\end{array}$} & Recording of logbook & Personal note making/working \\
\hline & Long term data logging & Overview of computer usage \\
\hline & Synch. screen capture & Detail of work carried out on computer \\
\hline \multirow{2}{*}{$\begin{array}{l}\text { Project management } \\
\text { activity }\end{array}$} & Long term data logging & Overview of computer usage \\
\hline & Synch. screen capture & Detail of work carried out on computer \\
\hline \multirow[t]{2}{*}{ Participant detail } & Synch. camera 1 & Visual of participant demeanour \\
\hline & Synch. camera 2 & Audio and visual participant demeanour \\
\hline Other & Work diary & Identifies events not otherwise recorded \\
\hline
\end{tabular}

\subsection{Data collection}

Data collection is split into three phases; acclimatization, study, and post-study. The standard setup and overall approach aims to minimise researcher/participant interaction throughout this process for two main reasons. First, this reduces the impact of the standard elements on the research specific aspects of the study. Second, minimising interaction reduces experimental effects. Essentially, the act of studying human subjects has a number of effects on their behaviour irrespective of study type (Kazdin 1998). These effects have many specific names and mechanisms of action (Holden 2001; Falk and Heckman 2009) but are generally referred to as Hawthorne type effects using the broad definition: "... The problem in field experiments that subjects' knowledge that they are in an experiment modifies their behaviour from what it would have been without the knowledge." (Adair 1984, 334). These effects can have a significant impact on participant behaviour and must be accounted for either in the study design or through control and normalisation (Diaper 1990; Cook 1962). In observational or descriptive studies this is achieved by minimising researcher/participant interaction (either through reduced contact, blinded research design or preferably both) and acclimatisation. Acclimatisation allows the participant to return to as close to normal behaviour as possible before starting the study. Although this has its own affect on the study (Adair 1984), 
acclimatisation has been shown to be key in reducing the influence of experimental effects (Podsakoff et al. 2003).

\subsubsection{Acclimatisation phase}

Acclimatisation serves several purposes in the foundational method:

1. It minimises experimental effects although further study is needed to validate this in the context of engineering design.

2. It allows participants to become accustomed to the research equipment and procedures, such as, the recorded logbook (Table 6). Two weeks was considered the minimum for allowing these to become habit based on McAlpine et al. (2011). In making the research procedure habitual the participant requires less direct monitoring, reducing interaction.

3. It allows the researcher to customize the standard technology setup, integrate any specific elements required, and address any issues raised by the participant. This includes checking the equipment and preliminary data - reducing problems/data loss during the study.

4. It allows the researcher to gather participant feedback on the perceived effectiveness of the capture strategy. Such, reflective feedback is a key tool for improving rigour (H. Robinson, Segal, and Sharp 2007).

It is suggested that participants undertake at least three weeks of acclimatization prior to the main study. This has been shown to be sufficient acclimatisation for the normalisation of Hawthorne and other effects (Leonard and Masatu 2006; Barnes 2010; Podsakoff et al. 2003). However, this can be extended or reduced and validated depending on the specific research design. In all cases the participants should record data and behave as they would during the main study, with the researcher checking the collected data for completeness at regular intervals. When the acclimatization period is very small in e.g. experiments or scenario based studies, control groups or other means should be used to account for the experimental effects. Overall (using acclimatisation or not) participant contact should be minimised and double blind designs used as best practice wherever possible. 


\subsubsection{Study phase}

With acclimatization complete the study phase should start immediately - lasting as long as required for the specific research aim. Before the study starts each participant is given the opportunity to talk through any remaining issues/questions. However, during the study itself participant/researcher interaction should be limited (Section 4.3.1). This minimisation is explicitly designed into the standard setup and overall method, with data collection automated where possible. At this point it is sufficient to recommend that researchers consider this when developing the research specific elements as further constraint could potentially limit the scope of possible research.

\subsubsection{Post study Phase}

Post study reflection - both immediately after the study, and with respect to the final analysis - is an important part in validating the completeness and accuracy of the data and findings ( $\mathrm{H}$. Robinson, Segal, and Sharp 2007). When applied after data analysis post-study interviews can be used to assess the validity of the results and conclusions, as well as to reflect on the success of the method itself. The foundational method employs semi-structured interviews to explore the following factors and conclude the study:

- It allows the researcher to check if the participants' perceived their working practices to have been in any way unusual during the study.

- It allows the researcher to check that participants were still hypothesis blind where appropriate.

- It allows participants to explain/expand on any incidents reported in the work diary and relate any issues or unrecorded events encountered during the study.

- It allows participants to provide one type of validation with respect to the conclusions drawn from the analysed data. 


\section{Coding Strategy}

The foundational methods multiple capture streams generate a large amount of data. It is emphasised that not all of this information need be immediately utilised, instead it forms the foundation for varied, multi-perspective reuse and reanalysis. As such, a streamlined approach is necessarily adopted in the proposed coding strategy, minimising workload whilst supporting comparison. This is realised using a multilevel strategy that facilitates the rapid narrowing of scope. Systematically linking specific situations with the wider information contextualising such periods.

\subsection{Multi-level coding and analysis strategy}

The multi-level coding strategy consists of five levels of increasing detail. The sequential levels act as filters, isolating periods that the researcher does not wish to explore further. This ensures that both the wider context and the detail required for the specific research aim are treated without overloading the researcher. Thus it is possible to describe the entire data corpus at Level 1 , and then subsequently narrow the scope by removing less relevant elements - as dictated by the researchers focus.

Figure 5 outlines the five levels, describing the focus and the filtering strategy at each level (filtered elements are italicized). Each level guides the selection of data to be coded at the next level, thus reflection on what should be removed at each stage is essential to the strategy's effectiveness. This is conceptually linked to Activity Theory, which describes a system where discreet periods of activity are defined using sequential levels of increasing detail, down to unconscious operations (Bedny and Harris 2005). The five levels proposed by the coding strategy complement this model. Here the situation in which an activity is taking place is described at various levels of detail. This supports comparison at any of the specified levels without prescribing or restricting the investigation of the hypothesis specific activity. In the context of engineering design, five levels have been defined and are considered to provide an appropriate balance between resolution and workload. More levels were considered excessively prescriptive whilst offering little further generalisability. 
Figure 5: Multi-level coding and analysis strategy

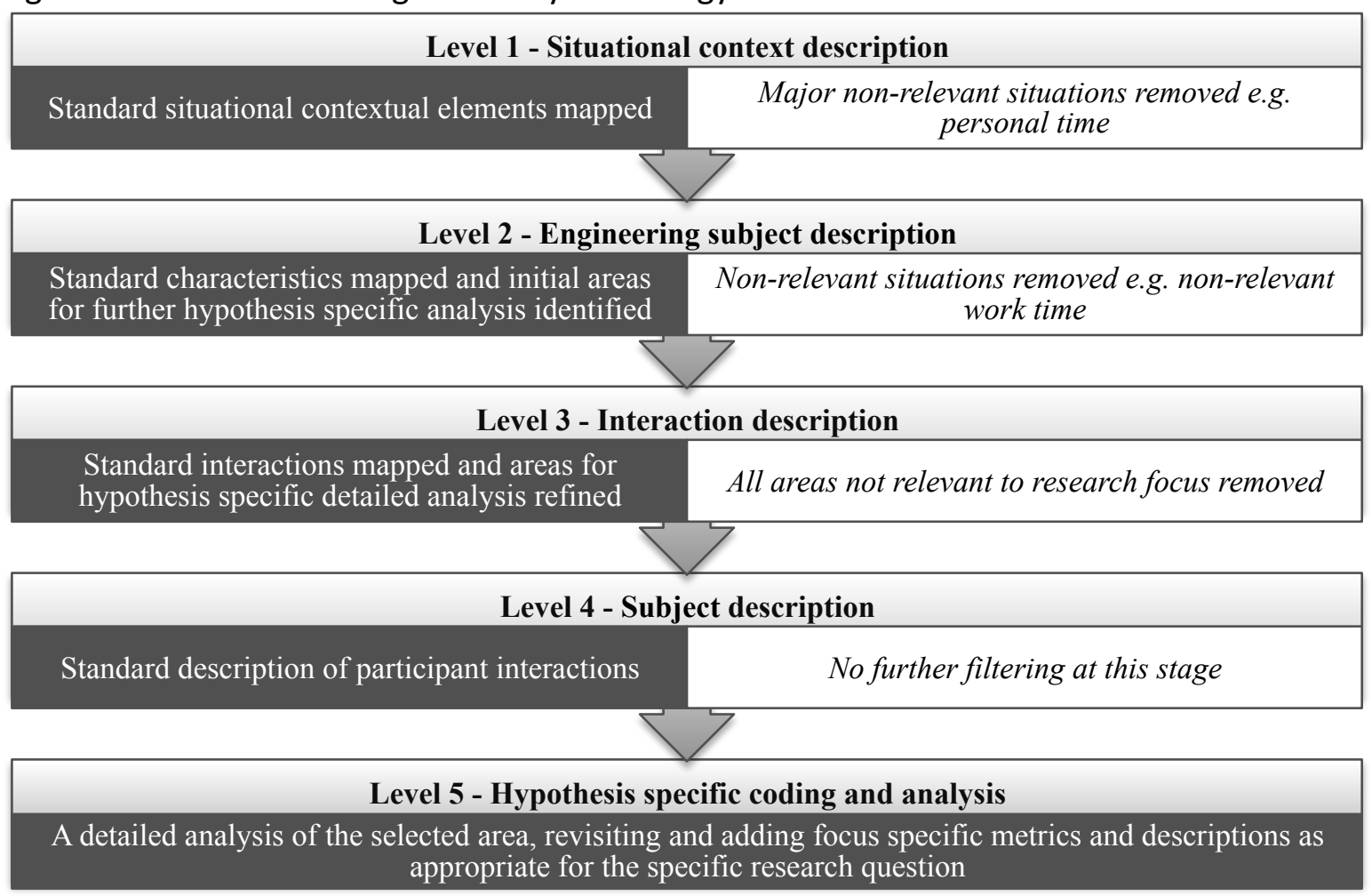

\subsection{Coding}

The multi-level coding has been designed to maximise its practicability whilst also giving maximum benefit to the researcher and the wider field. Only Level 1 is applied to the whole data set, with subsequent levels being applied to increasingly limited time periods. Further, the multi-level contextualisation of the final period (defined by the specific hypothesis) explicitly supports and promotes the triangulation of different studies, data, and approaches. Finally, the generality of the codes make them ideal for characterising a broad range of design situations, whilst also being applicable to a variety of research specific foci.

This has been achieved by the levels being designed to fulfil the key requirements for understanding and contextualising activity (defined by Activity Theory). Bedny and Harris (2005) describe two key characteristics for describing activity: object (a tool or material object that the subject or subjects interact with), and subject (two or more subjects are characterised in terms of information exchange, personal interaction, 
and mutual understanding). Combining this with the context discussion (Section 4.1) four areas emerge for defining an activity:

Situational context - the immediate work environment, the type of interaction being undertaken, and the participants' focus in terms of the generic engineering design process (Hales 1987). This also reflects a distinction between object and goal as discrete aspects of activity (Bedny and Harris 2005).

Engineering subject - the specific engineering design characteristics of the exchange between subjects: problem solving and information exchange. These have been established as applicable in the engineering domain by Wasiak et al. (2010) and Blandford and Attfield (2010). Here they have been adapted for generalisability by reflecting on the underpinnings of Activity Theory.

Interactions - the object(s) forming the primary focus of the activity, both individual and group. This has been generalised based on Cash et al. (2010).

Subject - the characteristics of exchanges between subjects: type of information exchange, personal interactions, and mutual understating (Bedny and Harris 2005). These have been based on the works of Horvath (2004) and Wasiak et al. (2010), and have again been generalised with regard to Activity Theory.

Table 7: The four levels of standard codes

\begin{tabular}{|l|l|l|l|}
\hline \multicolumn{2}{|l|}{ Level 1 Situational context } \\
\hline \hline Group & $\mathbf{N}^{\mathbf{0}}$ & Code & Code options \\
\hline $\begin{array}{l}\text { Interaction type } \\
1\end{array}$ & 1 & Individual/group & 0 - individual, 1 - group \\
\hline $\begin{array}{l}\text { Interaction type } \\
2\end{array}$ & 2 & $\begin{array}{l}\text { Synchronous/ } \\
\text { asynchronous }\end{array}$ & 0 - synchronous, 1 - asynchronous \\
\hline $\begin{array}{l}\text { Interaction type } \\
3\end{array}$ & 3 & $\begin{array}{l}\text { Co-located/ } \\
\text { distributed }\end{array}$ & 0 - co-located, 1 - distributed \\
\hline Environment & 4 & Location & 0 - normal, 1 - other \\
\hline
\end{tabular}




\begin{tabular}{|c|c|c|c|}
\hline Focus 1 & 5 & $\begin{array}{l}\text { Design process } \\
\text { stage }\end{array}$ & $\begin{array}{l}1 \text { - brief creation, } 2 \text { - feasibility, } 3 \text { - design development, } \\
4 \text { - manufacture, } 5 \text { - testing, } 6 \text { - reporting, } 7 \text { - other }\end{array}$ \\
\hline Focus 2 & 6 & $\begin{array}{l}\text { Focus: people / } \\
\text { product / process }\end{array}$ & 0 - other, 1 - people, 2 - product, 3 - process \\
\hline \multicolumn{4}{|c|}{ Level 2 Engineering subject } \\
\hline Group & № & Code & Code options \\
\hline \multirow[t]{8}{*}{ Problem solving } & 7 & Goal setting & 0 - not goal setting, 1 - goal setting \\
\hline & 8 & Constraining & 0 - not constraining, 1 - constraining \\
\hline & 9 & Exploring & 0 - not exploring, 1 - exploring \\
\hline & 10 & Solving & 0 - not solving, 1 - solving \\
\hline & 11 & Evaluating & 0 - not evaluating, 1 - evaluating \\
\hline & 12 & Decision making & 0 - not decision making, 1 - decision making \\
\hline & 13 & Reflection & 0 - not reflecting, 1 -reflecting \\
\hline & 14 & Debating & 0 - not debating, 1 - debating \\
\hline \multirow{5}{*}{$\begin{array}{l}\text { Information } \\
\text { exchange }\end{array}$} & 15 & Recognising need & 0 - not recognising need, 1 - recognising need \\
\hline & 16 & Interpretation & 0 - not interpreting, 1 - interpreting \\
\hline & 17 & Validation & 0 - not validating, 1 - validating \\
\hline & 18 & Seek/ request & 0 - neither, 1 - seeking, 2 - requesting \\
\hline & 19 & Using information & 0 - other, 1 - informing, 2 - clarifying, 3 - confirming \\
\hline $\begin{array}{l}\text { Management } \\
\text { exchange }\end{array}$ & 20 & Managing & 0 - not managing, 1 - managing \\
\hline \multicolumn{4}{|c|}{ Level 3 Interactions } \\
\hline Group & $\mathbf{N}^{-0}$ & Code & Code options \\
\hline \multirow[t]{3}{*}{ Audiovisual } & 21 & Audio only & \multirow[t]{3}{*}{0 - not interacting with $X, 1$ - interacting with $X$} \\
\hline & 22 & Visual only & \\
\hline & 23 & Audiovisual & \\
\hline \multirow[t]{2}{*}{ Documentation } & 24 & Formal & \multirow{2}{*}{$\begin{array}{l}0 \text { - not interacting with } X, 1 \text { - interacting with X } \\
\text { formal/informal split defined by Hicks et al. (2002) }\end{array}$} \\
\hline & 25 & Informal & \\
\hline \multirow[t]{3}{*}{ Physical } & 26 & Environment & \multirow[t]{3}{*}{0 - not interacting with $X, 1$ - interacting with $X$} \\
\hline & 27 & Tools & \\
\hline & 28 & $\begin{array}{l}\text { Design } \\
\text { representations }\end{array}$ & \\
\hline \multicolumn{4}{|l|}{ Level 4 Subject } \\
\hline Group & $\mathbf{N}^{-0}$ & Code & Code options \\
\hline $\begin{array}{l}\text { Type of } \\
\text { exchange }\end{array}$ & 29 & $\begin{array}{l}\text { Opinion/ } \\
\text { orientate/ } \\
\text { suggest }\end{array}$ & $\begin{array}{l}\text { giving or receiving: } 0 \text { - other, } 1 \text { - opinion, } 2 \text { - } \\
\text { orientation, } 3 \text { - suggestion }\end{array}$ \\
\hline Understanding & 30 & Agree/disagree & showing: 0 - other, 1 - agreement, 2 - disagreement \\
\hline Personal 1 & 31 & $\begin{array}{l}\text { Antagonism/ } \\
\text { solidarity }\end{array}$ & $\begin{array}{l}\text { giving or receiving: } 0-\text { other, } 1 \text { - antagonism, } 2- \\
\text { solidarity }\end{array}$ \\
\hline Personal 2 & 32 & $\begin{array}{l}\text { Tension/tension } \\
\text { release }\end{array}$ & showing: 0 - other, 1 - tension, 2 - tension release \\
\hline
\end{tabular}

In order to characterise each area, codes are defined over four sequential levels, summarised in 
Table 7 and defined in the appendix. Each level is split into groups for clarity. Within each group codes are mutually exclusive. Level 5 is flexible and is thus not included in

Table 7.

\section{Analysis Strategy}

The intent of the analysis strategy is not to fully analyse all the data captured and coded in Sections 4 and 5. Instead, analysis is again tackled in sequential stages. This avoids overloading the researcher whilst maintaining traceability and analytical rigour. In order to achieve this result there are a number of standard steps required to ensure rigour and completeness: alignment, layered analysis, and reflection.

First, the data sources need to be aligned on a single persistent timeline as emphasised by Torlind et al. (1999; 2009). For maximum benefit both standard and research specific sources should be aligned to a common timeline. This allows the researcher to increase the potential of complementary data sources in three ways:

- It allows gaps in one source to be filled by another e.g. using mobile camera footage to follow the participant when they leave their desk - developing a more complete record.

- It allows multiple coded sources to be compared for a single event e.g. the coding for the participant's logbook could be compared to the coding for the camera in order to refine the final result - developing a more rigorous record. 
- It forms a better foundation for generalisability, replication, and reuse by relating the standard and flexible elements of the study to a single core unit - in this case the common timeline.

Synchronisation and alignment requires a core timeline for consistency. For example, using the standard record of the computer screen (Table 6) as a master timeline in VCode (Hagedorn, Hailpern, and Karahalios 2008) (or similar annotation tools) all other sources, both standard and flexible, can be combined. Although the primary source is not prescribed, and need not be one of the standard sources, it is recommended that the selected source is the most individually complete and comprehensive - minimising additional combinatory work. Further to the methodological advantages of combining the sources onto a single master timeline this also streamlines the analysis, export, and comparison tasks. With the various data sources aligned it is possible to start the analysis. The foundational method utilises three levels of detail and complexity.

The first and least complex level is the high-level quantification of the standard codes. This can include the total time each code accounted for, the number of instances, and overall trends. This high-level analysis follows the same approach and structure as outlined in

Figure 5 i.e. analyse codes level by level, sequentially omitting areas not of interest as required. This allows for a standard baseline to be created, against which other studies using the foundational method can be compared.

Second, with the high-level analysis complete consider groupings of related standard codes. This level can be used to draw out deeper comparisons and to define more complex activities or situations. For example, using a combination of standard codes to describe a key situation allows for the subsequent identification of similar situations in other datasets utilising the foundational method. As such, this provides the basis for multi-perspective examination and triangulation. This again allows pattern, frequency, total time or other aspects to be analysed for each group of codes. Groups are identified based on the following standard steps; illustrated using the comparison study (Section 7) as an exemplar: 
1. Develop descriptive definitions of areas of interest - in this case tasks within the engineering design process as defined by Hales (1987).

2. Allow groups of codes to emerge from the data for the defined areas of interest (this can include multiple groupings) - In this case, conceptual design is defined using six combinations of codes. For example, two groups are: 'group', 'design dev', 'focus - product', 'exploring', referring to a group brainstorming activity; and 'individual, 'design dev', 'focus - product', 'exploring' referring to an individual ideation activity.

3. Reflect on the allocation of the groups of codes to ensure that the selected definitions are appropriate and further definitions do not need to be considered for the given research focus. This is an important step as there can be large numbers of combinations for a single definition (depending on the code level to which the groupings are defined).

Third, the standard codes can form the basis for the detailed analysis if they are considered sufficient for the research specific focus of the study (Level 5).

Once the analysis is complete it is necessary to reflect on the validity, reliability, and limitations of the data. However, as the focus of the foundational method is on supporting replication and comparison rather than explicitly addressing internal validity, the means by which the researcher establishes these parameters (validity, reliability, limitations etc.) is flexible. With respect to the foundational method it is sufficient to establish that the information that has been coded is representative of the data. As such, appropriate inter-coder reliability checks should be undertaken.

\section{A Comparison Study}

In order to explore the utility of the foundational method in the context of design research the comparison study explores two perspectives. These perspectives are necessary in order to more fully assess the ability of the method to support comparison between studies that are related but distinct - one of the primary motivations for this work. Both perspectives are supported by the comparison of an 
industrial study and an experimental study (the same studies are used for both perspectives).

The first perspective considers the method's potential for comparing and triangulating studies of different formats. Here the format is considered to include the setting (laboratory, intermediary or practice), the population (e.g. student or practitioner), and the type of approach used (fully contrived experiment, quasiexperiment, practice based case etc.). The second perspective considers the method's applicability to varied research foci. Here the research focus is considered to mean the main subject of investigation as well as the overall aim of the research (e.g. descriptive or prescriptive). Format and research focus were considered the key differentiators between studies and thus selected as the basis for the comparisons outlined in this section. Further, the comparison between the reported studies constitutes a real research need. Specifically, the research aim was to compare design activity in a range of design situations across research settings. However, this is not the focus of the work here and has been fully reported elsewhere in Cash et al. (2013). A summary of the two studies has been included below in order to contextualise the comparison.

\section{Summary of Industrial Study}

The population (seven designers in 18 staff) was introduced to the research through a series of introductory meetings and a sample size of three was selected. Three was considered appropriate because the company used a matrix structure where all engineers work across multiple projects. Participants were then asked to volunteer due to the intensive nature of the observation. Five volunteered and three were selected randomly, representing each seniority level i.e. junior, midlevel, and senior. Each participant was then observed for four weeks total (three weeks of acclimatisation and one week of study). Only one participant was observed at a time and there was no overlap in terms of projects or collaboration - each participant worked independently of the others. In terms of technical setup the full suite of capture approaches was used as described in Section 4.2. This resulted in a total of three weeks of study data amounting to circa 300 hours of video (due to the multiple sources) and circa $100 \mathrm{~GB}$ of data after compression. Participants were observed, coded, and analysed in a random order, with all data sources synchronised. 


\section{Summary of Experimental Study}

The population for this study was selected from a group of 40 final year masters level engineering students. From this population, twelve students were selected and randomly assigned to one of four teams. All participants were given creativity and sociometric tests in order to form a baseline.

Each team was then given the following brief: "You are to design a universal camera mount for use on an aerial vehicle. The aerial vehicle is to be used by an amateur photographer, primarily to take still photos." In completing this brief the session was split into four phases: (1) 50 minutes individual information seeking, (2) 50 minutes group ideation, (3) 90 minutes individual design development, and (4) 50 minutes design review.

\subsection{Perspective 1: Study Format}

The objective of this comparison is to verify the applicability of the foundational method across a range of formats as well as to establish its utility in the comparison and aggregation of data across related studies. Both studies were carried out based on the foundational method with adaptations for the specific setting and research aims.

For the industrial study the situations described fully at Level 4 are contextualised by the preceding levels and can be defined in terms of combinations of codes. The subaim of the industrial study was to identify and characterise key design situations, such as, ideation and design review meetings, contributing to the overall comparative aim described above. As such, the coding schema allowed for the rapid narrowing of scope while retaining the overview of the whole study period.

This progression can be illustrated using the industrial study example. First, the majority of the study (240 hours - see Table 8 ) was coded coarsely at Levels 1 and 2 (average time per code $=680$ seconds compared to Level 4 where the average time per code $=17$ seconds). Results were tabulated and a Visual Basic script used to automatically identify and list all the unique combinations of codes. This resulted in 147 combinations, which could be described as unique situations. Next, the combinations were grouped by defining key features for further analysis (described in detail in Section 7.2) and confirmed by checking the identified combinations 
against the original footage. This example led to ten high-level situation types, with the design related situations summarised in Table 9. Finally, an automated check was used to reveal any periods that could be assigned to more than one overall group (14 in total), which could then be rapidly identified and clarified.

Conversely, the experimental study was defined in detail by its associated research aims (see Section 7.2) and could thus be immediately characterised by the standard coding elements. To elaborate, the higher levels of the coding strategy were predefined or highly limited by the research aim and were therefore used descriptively. Further, as the higher levels could be coded rapidly specific codes could be examined with little additional effort.

Table 8 describes how the foundational method was applied to each of the studies. This highlights how it can be adapted, streamlined, and applied to different contexts whilst retaining comparability. For example, overall participant context was captured for both studies - allowing for comparison of populations. In the industrial study this information was captured prior to the study using questionnaires as the aim was descriptive and thus hypothesis blindness was not an issue. In the experimental study overall participant context was recorded post study to avoid biasing the participants and was complemented by specific tests required for the research aim.

A key feature of the foundational method, highlighted by Table 8 , is that the experimental study can be immediately and directly related to similarly contextualised situations from the industrial study. For example, periods of ideation from the industrial study could be explicitly identified and compared to ideation during the experimental study. This is born out when the data from the experimental and industrial studies is compared. An example comparison is shown in Figure 6, which shows the similarity in ideation between the industrial study and the experimental study.

Table 8: The two studies in relation to the foundational method

\begin{tabular}{|r|l|l|}
\hline $\begin{array}{l}\text { Foundational } \\
\text { method }\end{array}$ & Industrial study & Experimental study \\
\hline \hline \multicolumn{2}{|c|}{ Overall context } \\
\hline \hline Personal & $\begin{array}{l}\text { Carried out prior to the study using } \\
\text { questionnaires as no fixed hypothesis } \\
\text { population }\end{array}$ & $\begin{array}{l}\text { Carried out post study to maintain } \\
\text { hypothesis blindness using } \\
\text { questionnaires and other tests for } \\
\text { hypothesis specific information }\end{array}$ \\
\hline
\end{tabular}




\begin{tabular}{|c|c|c|}
\hline Technical setup & As prescribed & $\begin{array}{l}\text { As prescribed but forgoing mobile } \\
\text { cameras due to the restricted setting }\end{array}$ \\
\hline \multicolumn{3}{|c|}{ Capture } \\
\hline Acclimatisation & $\begin{array}{l}\text { Three weeks for each participant to } \\
\text { minimise effects }\end{array}$ & $\begin{array}{l}\text { None due to the study design, instead } \\
\text { control groups could be used }\end{array}$ \\
\hline Study & $\begin{array}{l}\text { One week per participant with full } \\
\text { freedom ( } 98 \text { hours total for the three) }\end{array}$ & $\begin{array}{l}\text { Four hours with each experimental } \\
\text { team - predefined group and individual } \\
\text { work }\end{array}$ \\
\hline Post study & $\begin{array}{l}\text { Interview assessing the data, and } \\
\text { reported work of the participant }\end{array}$ & None \\
\hline \multicolumn{3}{|c|}{ Coding } \\
\hline Level 1 & $100 \%$ of time coded at this level & $\begin{array}{l}\text { Specified by the study design thus not } \\
\text { coded }\end{array}$ \\
\hline Level 2 & $80 \%$ of the time coded at this level & $\begin{array}{l}\text { Guided by the study design, only a } \\
\text { selection of codes were encountered ( } 4 \\
\text { of } 14 \text { Level } 2 \text { codes used) }\end{array}$ \\
\hline Level 3 & $\begin{array}{l}\text { Focus reduced to group work with a } \\
\text { focus on the product: } 34 \% \text { coded }\end{array}$ & $\begin{array}{l}\text { Guided by the study design, only a } \\
\text { selection of codes were encountered ( } 2 \\
\text { of } 8 \text { Level } 3 \text { codes used) }\end{array}$ \\
\hline Level 4 & $\begin{array}{l}\text { Specific situations: only } 4.2 \% \text { coded: } \\
\text { one ideation, one information seeking } \\
\text { and one review situation ( } 250 \mathrm{~min})\end{array}$ & Coded fully for each of the studies \\
\hline Specific & $\begin{array}{l}\text { None originally - then specific codes } \\
\text { from the experiment applied situations } \\
\text { in the industrial study }\end{array}$ & $\begin{array}{l}\text { Additional codes added for ideation, } \\
\text { information seeking and design review } \\
\text { based on the research questions }\end{array}$ \\
\hline \multicolumn{3}{|c|}{ Analysis } \\
\hline Synchronisation & $\begin{array}{l}\text { As prescribed, using the participant } \\
\text { camera as the central timeline }\end{array}$ & $\begin{array}{l}\text { As prescribed, using the participant } \\
\text { camera as the central timeline }\end{array}$ \\
\hline High level & $\begin{array}{l}\text { Individual codes used to describe } \\
\text { overall design activity and process }\end{array}$ & $\begin{array}{l}\text { Level } 1 \text { used to compare experimental } \\
\text { context to industrial study }\end{array}$ \\
\hline Groupings & $\begin{array}{l}\text { Groups of codes used to describe } \\
\text { specific situations for comparison - } \\
\text { ideation, seeking and review }\end{array}$ & $\begin{array}{l}\text { Guided codes (Level } 2 \text { and } 3 \text { ) used to } \\
\text { link to the specific situations observed } \\
\text { in practice }\end{array}$ \\
\hline $\begin{array}{l}\text { Detailed } \\
\text { analysis }\end{array}$ & \multicolumn{2}{|c|}{$\begin{array}{l}\text { Specific codes analysed and then applied to the identified analogues situations } \\
\text { from the industrial study - ideation, seeking and review }\end{array}$} \\
\hline Reliability & $\begin{array}{l}\text { Cohen's Kappa applied to check inter- } \\
\text { coder reliability }\end{array}$ & $\begin{array}{l}\text { Cohen's Kappa applied to check inter- } \\
\text { coder reliability }\end{array}$ \\
\hline
\end{tabular}

Figure 6: Ideation in the industrial study and in the experimental study 


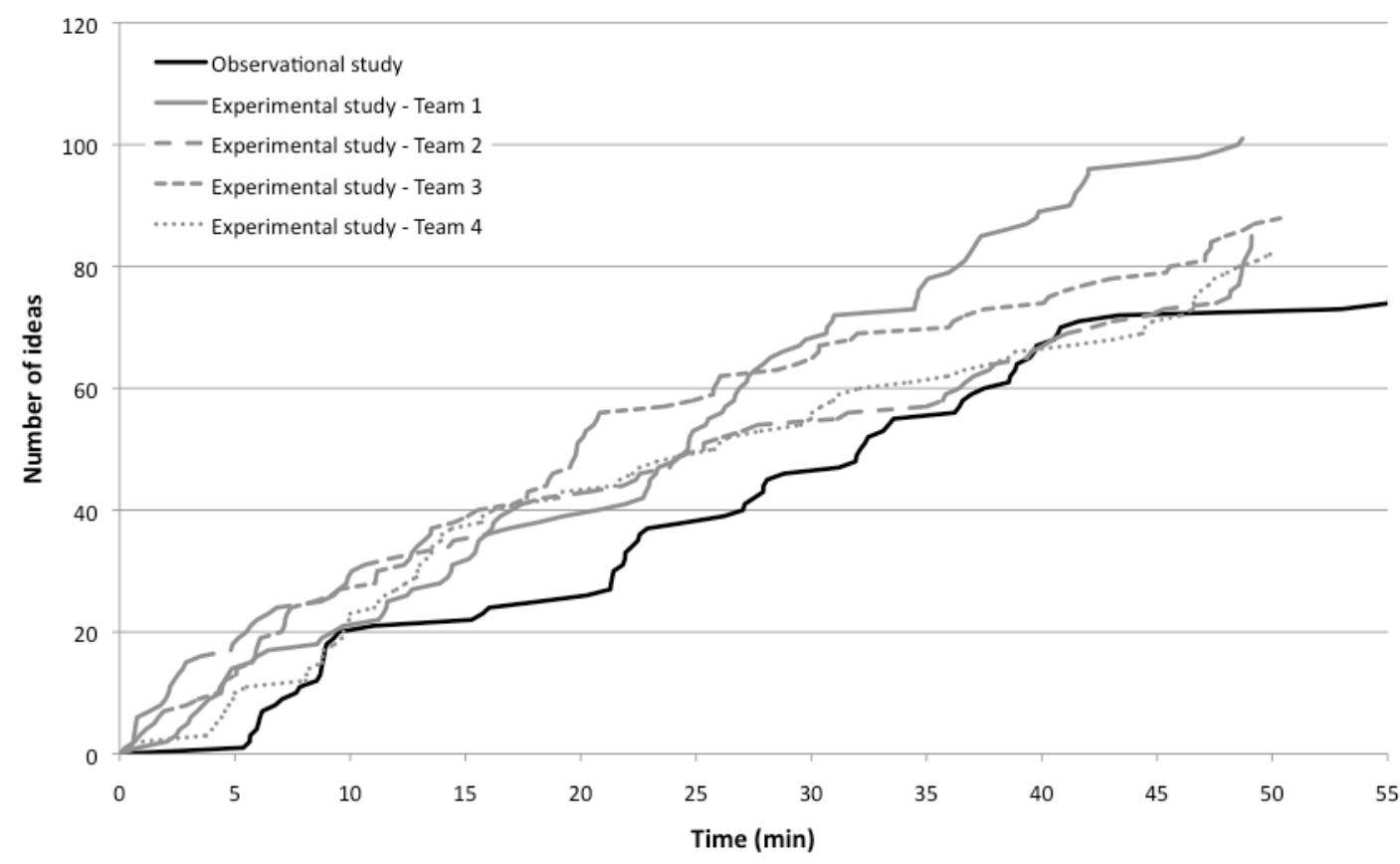

By enabling this comparison the method allows for an improved assessment of the likely impact of findings from the experimental study in practice. Here, the features of the experimental study (e.g. information seeking) can be explicitly mapped to similar periods in practice. The potential impact from changes in these periods can then be assessed holistically. Figure 7 highlights three examples of such mappings, which are denoted by the circular overlays. These are explicitly and directly linked to the situations described in the experimental study. Specifically, Figure 7 shows information seeking, design development, and design review activity in the industrial study (based on Levels $1-4$ ). This shows how these isolated regions can now be assessed with respect to their role in the wider process.

Figure 7: Identifying relations between the studies 


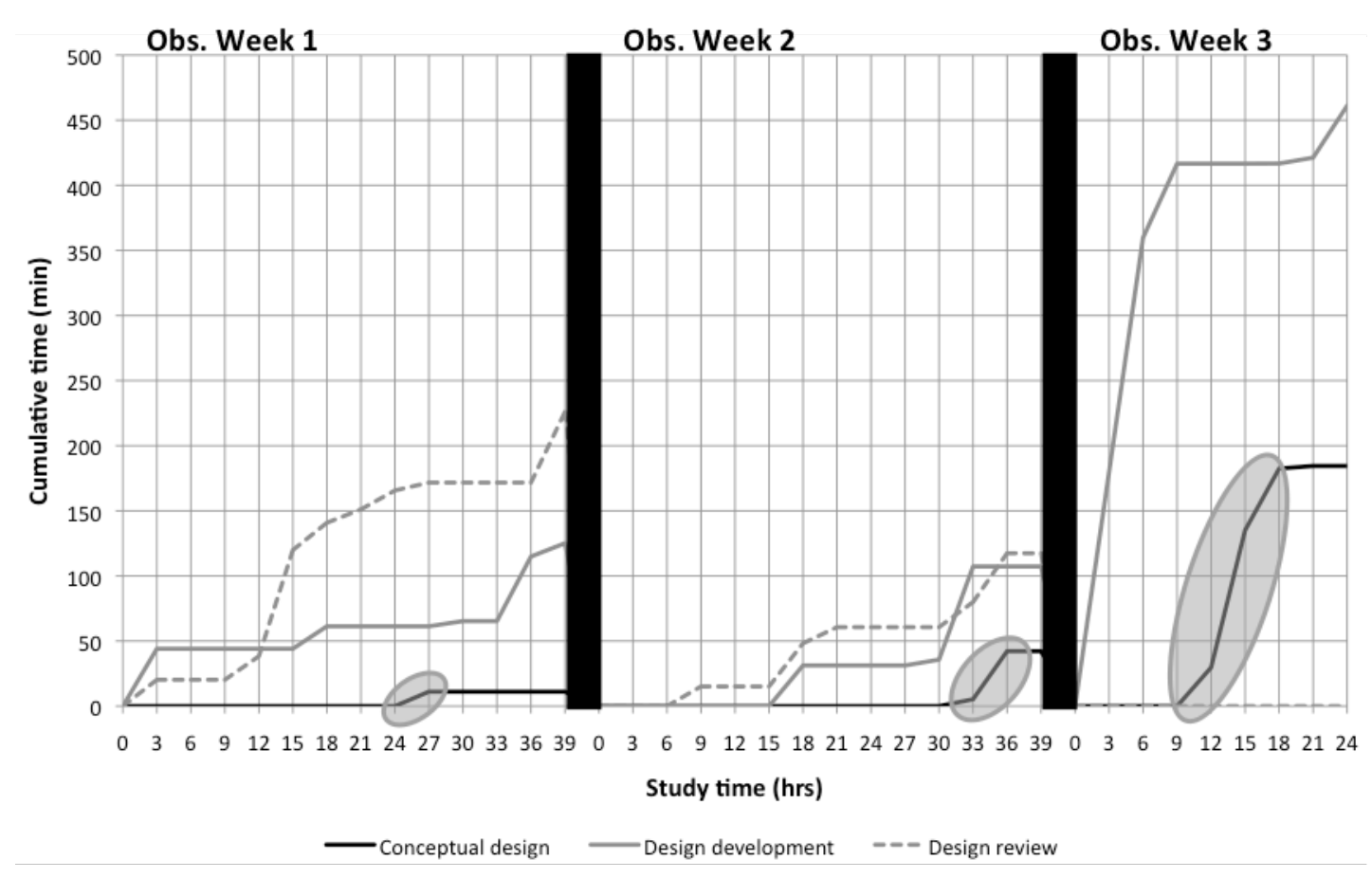

\subsection{Perspective 2: Research Focus}

In this context four different research foci were considered: the overall design process, information seeking, ideation, and design review. The objective of this comparison is to verify the flexibility of the foundational method in supporting a range of different research foci.

\subsubsection{Design process}

The industrial study was used to assess the ability of the foundational method to support a purely descriptive focus. Here, the aim was description of the design process based on the standard analytical steps (Section 6). First, the individual codes allowed for a raw assessment of the types of work undertaken using the total time spent on each activity e.g. product, process or people, and the design phase.

Second, combining the codes allowed for a more nuanced description of the design process and participant activity. With respect to the example of information seeking it allowed for the whole range of information behaviours characterised by Robinson (2010) to be described in terms of combinations of codes. This resulted in approximately $45 \%$ of the participants' time being associated with information seeking activities of various types. This closely, links to other estimates of information seeking in the extant literature (Robinson (2010) - 56\%, King et al. 
(1994) - 40-60\%, Puttre (1991) - 32\%, and Cave and Noble (1986) - 30\%). This suggests that the combination of standard codes was in fact sufficient to fully represent this specific research focus. An example of a combination of standard codes used to describe one type of information seeking activity is (the number of the relevant code is given in brackets (Table 7)): Individual (1), distributed (3), feasibility stage (5), product focus (6), solving (10), and requesting information (18). In this case the standard coding could allow Robinson or others to reanalyse the data with respect to their own work without significant recoding effort. Instead reanalysis is achieved either by defining combinations of codes or by identifying areas of interest and then recoding them specifically.

This process of identifying extant research foci from the literature and then using these to define code groupings was used to assess the flexibility of the foundational method for each stage of the design process (Hales 1987). 
Table 9 summarises the stages and the literature used in assessing the foundational method's application to each. This allowed for each stage to be mapped across the study period and to be evaluated both individually and collectively (Figure 8). Although additional work was required to code the extra information at each level of the schema, it subsequently gave significant scope for reanalysis and reappraisal. More specifically, the foundational method increased the time required for the initial coding by approximately a third, expanding on the original codes rather than demanding a whole new analysis. However, the multifaceted coding reduced reanalysis time - allowing the data to be fed into a range of different research foci including ideation, information seeking, and design review. Building on the multilevel coding allowed these to be assessed automatically with additional codes added only where necessary - reducing the overall workload significantly. 
Table 9: Hales' (1987) stages of the design process related to the foundational method

\begin{tabular}{|c|c|}
\hline Stage & Description \\
\hline $\begin{array}{l}\text { Conceptual } \\
\text { design }\end{array}$ & $\begin{array}{l}\text { Ideation and concept development tasks inc. brainstorming, idea selection } \\
\text { and concept exploration (Howard 2008; Cash et al. 2011) }\end{array}$ \\
\hline $\begin{array}{l}\text { Design } \\
\text { development }\end{array}$ & $\begin{array}{l}\text { Development of a specific final concept inc. design refinement and problem } \\
\text { solving (Carrizosa and Sheppard 2000; Kim and Maher 2008) }\end{array}$ \\
\hline Design review & $\begin{array}{l}\text { Reviewing existing work or future planning inc. review meetings and } \\
\text { reflection on current designs (Huet, McMahon, et al. 2007; D'Astous et al. } \\
\text { 2004) }\end{array}$ \\
\hline $\begin{array}{l}\text { Embodiment } \\
\text { design }\end{array}$ & $\begin{array}{l}\text { Technical layouts and CAD configurations inc. CAD, prototyping and } \\
\text { configuration (Scaravetti and Sebastian 2009; Chenouard, Sebastian, and } \\
\text { Granvilliers 2007) }\end{array}$ \\
\hline Testing & Not considered as not present in the industrial study \\
\hline $\begin{array}{l}\text { Project } \\
\text { reporting }\end{array}$ & $\begin{array}{l}\text { Formal collation and dissemination of structured reports inc. lessons } \\
\text { learned, reports and formal presentations (Wild et al. 2005; Haas, Weber, } \\
\text { and Panwar 2000) }\end{array}$ \\
\hline $\begin{array}{l}\text { Information } \\
\text { seeking }\end{array}$ & $\begin{array}{l}\text { Searching, requesting, synthesizing and evaluating information inc. } \\
\text { examination of records and applying data (M. A. Robinson 2010; King, } \\
\text { Casto, and Jones 1994) }\end{array}$ \\
\hline Dissemination & $\begin{array}{l}\text { Informal communication of decisions, plans or progress inc. email, } \\
\text { conversations and shared workspace (McAlpine 2010; McAlpine, Hicks, and } \\
\text { Culley 2009) }\end{array}$ \\
\hline
\end{tabular}

Figure 8: Overall participant activity during the industrial study

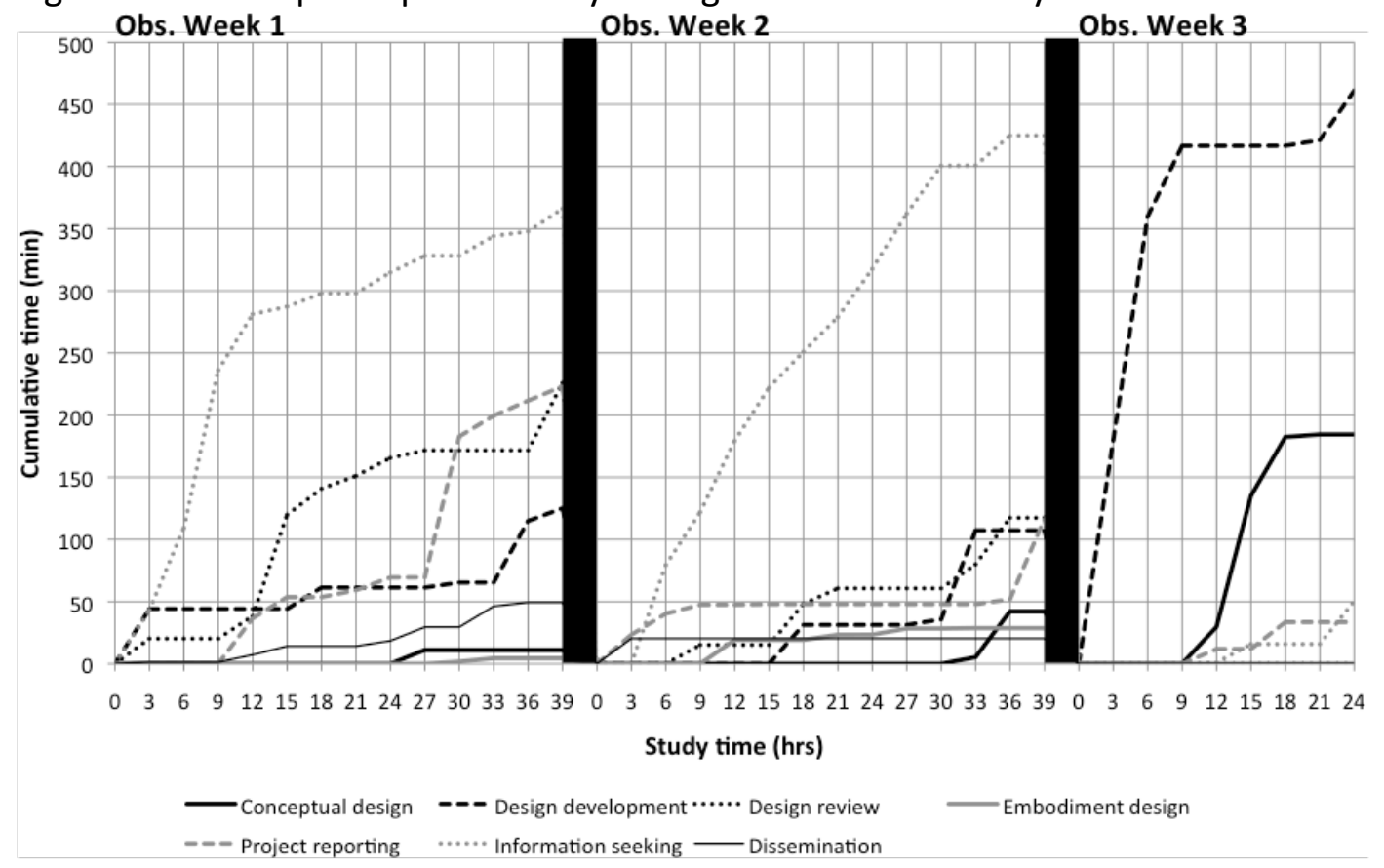

With respect to the different research foci three main areas were considered for comparison across the studies. 


\subsubsection{Information seeking}

This example examined the role of information seeking activity and sources on design performance. Here, the situational context was described as 5 (design development stage), 7 (product focused), and 10 (solving) with either 18 (seeking/requesting) or 16 (interpretation) denoting information exchange. The Level 5 codes, based on the work of Robinson (2010), served as the basis of comparison when examining the results.

\subsubsection{Ideation}

This example examined the need for creative stimuli by assessing the change in the rate of idea generation over time. Here, the situational context was defined as codes 1 (group), 4 (in a meeting room), 5 (feasibility stage), 6 (product focused), and either 9 (exploring the problem) or 10 (solving the problem). Further, the work of Howard et al. (2010) was also characterised using the standard method - facilitating a comparison to this existing dataset from practice. As such, the only Level 5 code was for idea generation. An example of the results is given in Figure 6.

\subsubsection{Design Review}

This example focused on the use of artefacts during a design review meeting. Here, the codes 1, 4, 5, and 6 were used to define the situational context while Level 2 and 3 codes were used as the basis for the analysis. The results were then compared to the work of Huet et al. (2007).

\section{Discussion}

This section outlines the theoretical contributions associated with each aspect of the method before offering an overall critique of its limitations and its potential impact on the design research field. 


\subsection{The Foundational Method}

The foundational method proposed in this paper aimed to improve the replication, reuse, and comparability of empirical design studies. This was achieved by addressing the specific problems identified in Table 2: linking to theory, describing context, sampling design, research design, data collection, reflexivity, analysis, and value of findings. The foundational method combines the benefits of both standard and flexible elements using multi-level capture, coding, and analysis. This allows the flexible examination of research specific detail whilst also providing rich contextualisation of the situation under study, a standardised dataset, and a means of comparison and triangulation.

The capture step first formalises the reporting of overall context in four areas activity/technical, social, cultural, and historical. Second, the standard multiperspective capture approach defines numerous complementary sources. Finally, an acclimatisation period is incorporated into the typical observational approach to reduce experimental effects. These support the generation of a broad and robust dataset, which can be analysed at multiple levels of detail from a wide range of specific research foci.

The multilevel coding strategy allows for a streamlined contextualisation of the wider study and minimal restriction of flexibility by progressive filtering at each of the four coding levels. This enables a rapid interrogation (and comparison) of the dataset at multiple levels of detail whilst maintaining context and methodological robustness, and minimising additional workload.

The corresponding multi-level analysis provides a standard foundation for replication, reuse, and comparison by aligning and baselining the dataset. Further, the analysis strategy allows the researcher to interrogate the data at increasing levels of detail with relatively little additional effort. This enables an analysis of the coded data, which supports both high-level contextualisation and rapid analysis of large bodies of data while also supporting flexibility and overall rigour.

\subsection{Improving design research methods}

The three steps combined in the foundational method support the standardisation of key comparative data for a wide range of studies. Section 7 considers a 
comparison between an industrial and an experimental study. This capability is critical to improving reuse and laying the foundation for meaningful comparison and triangulation of data/findings - all key areas for the improvement of design research methods (Blessing and Chakrabarti 2009). Further, the foundational method offers the pragmatic benefit of allowing the researcher to more effectively structure and navigate through the large amounts of data generated in observational studies and significantly expands on the recommendations of Blessing et al. (1998). For example, the narrowing of focus from 32 codes and 240 hours of study, through to 147 unique code combinations, and finally ten situations can be examined and reanalysed at any stage without any further coding. Finally, the multilevel approach allows the foundational method to be flexible in terms of research focus without sacrificing the benefits of standardisation or rigour, as highlighted by the comparison study and discussed throughout.

It is proposed that by taking the first step towards a standardised approach for design research the foundational method contributes directly to the development of methodological and evidential standards in the field. It is unlikely that serious progress will be made in these areas without a bottom up drive for improved methods and standards, motivated by researchers and underpinned by tangible benefits - as has been the case in other fields e.g. education (Gorard and Cook 2007) or policy research (Brennan et al. 2011).

\subsection{Reducing research bias}

A second area where the method contributes is in the mitigation of researcher bias. Despite there being significant scope for researcher flexibility, the multi-level coding and analysis facilitate the recording of data selection at each level, and the tracing of analytical logic as researchers focus in on the main area of interest. For example, the 147 code combinations of the presented comparative study (Section 7) can each be explicitly described and examined in order to assess coder reliability and facilitate reinterpretation of the data. As such, systematic bias can be more easily traced and accounted for when reusing the data. Further, it provides a fuller record of coding and analysis steps than the typical approach where only the key focus area is considered - lacking the rich contextualisation and foundation provided by the 
foundational method. Typically this is not reported, making it difficult to assess how situations have been selected or are linked to the wider process. It should be noted that as this method builds on coding based approaches it is not possible to eliminate researcher bias and, as such, promotes a philosophy of transparency.

\subsection{Evolution of the foundational method}

In terms of longevity, this paper forms one of the first tangible propositions in the discussion of standard methods in design research. This makes for an inherently evolving dynamic environment. Thus, despite the foundational method being designed based on fundamental research issues (Table 2 ) it is to be expected that as the scientific debate evolves, so will the foundational method. Just as the Randomised Controlled Trial (RCT) (a major standard for clinical research design (Devereaux and Yusuf 2003)) did not emerge in its final form upon conception, the foundational method contributes to an on going debate key to the methodological future of design research. Thus, despite the RCT evolving over time its conception is fundamentally robust, because it was built on a foundation of explicitly addressing core research issues. As such, it is envisaged that even as new methods and good practices evolve in design research, the baselining and aggregation of studies will never be a negative. Further, although research needs and standards may change, fundamental aspects of design will not i.e. the multi-level coding. Thus, the very nature of the foundational method provides a baseline for future comparison, forming a foundation of data and good practice that can be built upon and matured as the field grows, without restricting the development of new and improved methods.

Finally, there are numerous alternative solutions to the issues described in Table 2, hence the complexity of the debate surrounding good research practice. Two key alternatives include improved education of researchers and standardised selection systems for methods or variables. Although the first is clearly a viable alternative it does not supersede the proposed work, instead it offers a complementary means of improvement. Indeed, a key element in education is identifying best practice and training towards effective and meaningful standards, as well as, in the use of recognised methods e.g. the RCT in medical research. As such, the foundational 
method both guides and complements teaching efforts. Second, both a standardised selection system and the foundational method aim to address the same issues and are therefore complementary whilst offering alternative solutions depending on the evolving research context. However, at time of writing, no such selection system exists in the design research domain, and thus offers a major area for further work. While out of the scope of this paper, meaningful field wide methodological standards and overall improvement are only likely to come from focused discussion and the proposal, comparison, and synthesis of a range of approaches. For example, consider the debate between alternative approaches articulated by Gorard and Cook (2007). Here, despite each individual approach being successful it took many decades and iterations before they were recognised as being complementary and subsequently combined.

In summary it is posited that the foundational method addresses many of the problems identified in Table 2, however, there is still need for further work. This is summarised in

Table 10, which highlights how the problems (Table 2) have been addressed and where the need for further work has been identified.

Table 10: Issues and their mitigation by the foundational method

\begin{tabular}{|c|l|}
\hline Problem & Description of mitigation \\
\hline 1. Linking to theory & $\begin{array}{l}\text { Contextualisation and multi-level analysis allow situations to be linked to } \\
\text { existing work and wider theory by offering a standard basis for comparison }\end{array}$ \\
\hline 2. Describing context & $\begin{array}{l}\text { The overall contextual information and multilevel coding built on situational } \\
\text { context significantly improves description of the hypothesis specific elements }\end{array}$ \\
\hline Further work & $\begin{array}{l}\text { This requires further development in order to identify what specific } \\
\text { information is most valuable when recording context in the design domain }\end{array}$ \\
\hline 3. Sampling design & $\begin{array}{l}\text { This is addressed by the standard contextualisation of population and allows } \\
\text { for more effective comparison and triangulation of similarly described studies }\end{array}$ \\
\hline Further work & $\begin{array}{l}\text { There is a need to develop and validate the links between sample design and } \\
\text { the elicited contextual information }\end{array}$ \\
\hline $\begin{array}{l}\text { 4. Clarity of research } \\
\text { design }\end{array}$ & $\begin{array}{l}\text { Description of the coding schema and the ability to define the level or area of } \\
\text { analysis from combinations of codes supports standardisation and clarity }\end{array}$ \\
\hline Further work & $\begin{array}{l}\text { There is need for significant work in the development of links between levels } \\
\text { and the development of relationships between individual and groups of codes }\end{array}$ \\
\hline $\begin{array}{l}\text { 5. Mitigation of bias } \\
\text { in data collection }\end{array}$ & $\begin{array}{l}\text { The acclimatisation period and multimodal capture allow for reduced } \\
\text { experimental effects and triangulation of multiple sources, reducing bias }\end{array}$ \\
\hline 6. Reflexivity & $\begin{array}{l}\text { The semi-automated nature of the capture strategy eliminates the need for } \\
\text { researcher/participant interaction during the study period }\end{array}$ \\
\hline $\begin{array}{l}\text { Work is needed to understand the impact of experimental effects over time } \\
\text { in the engineering design domain and to subsequently optimise } \\
\text { acclimatisation }\end{array}$ \\
\hline
\end{tabular}




\begin{tabular}{|l|l|}
\hline 7. Data analysis & $\begin{array}{l}\text { Multilevel coding and analysis coupled with multimodal capture allow } \\
\text { characterisation of the system at multiple levels of detail reducing bias }\end{array}$ \\
\hline 8. Value of findings & $\begin{array}{l}\text { The ability to give detailed analysis for selected situations while retaining } \\
\text { high-level contextual information supports replication, reuse, triangulation } \\
\text { and critique - key areas for improving theory and research uptake }\end{array}$ \\
\hline
\end{tabular}

\subsection{Constraints and limitations}

There are several limitations of the foundational method. The primary weakness is in validating the range of possible participant/case sample sizes to which the foundational method can be applied. However, the multilevel approach allows the researcher to define the sample size required (from statistically significant to single case) and then apply the appropriate level of coding and analysis without losing the advantages of standardisation, contextualisation, and additional detailing.

A second issue requiring further investigation is the period of acclimatization. Although this has been the focus of some investigation in other fields there is little information on the amount of time needed and specific effects encountered in the engineering design domain. An improvement would be to carry out a series of studies to explicitly determine the extent of the disruption caused by experimental setup and the length of time required for participants to return to normal practice. In the context of the comparison study the acclimatisation period was considered sufficient as evidenced by participant's checking private emails and other personal activities. However, for each study the acclimatisation period should be designed accordingly. It should also be emphasised that this ought to be supported with double blind design as best practice.

Third, although the foundational method does introduce some additional methodological and standardisation demands the strategy allows the method to be rapidly adapted to most observation research contexts. This has been demonstrated via the comparative study (Section 7) where information seeking, ideation, and design review were all examined. However, the true scope of the flexibility of the foundational method in terms of sample, compatible research topic, and approach are yet to be fully validated, and form a key opportunity for further study.

Fourth, due to the nature of grounded, qualitative, and mixed-method studies systematic statistical comparison of results is philosophically difficult - particularly grounded qualitative studies. However, a central thesis of this approach is that with 
better description of the context in which results are generated and a systematic means of baselining populations, more considered aggregation of data could be attempted. This allows for cross study comparisons as opposed to the current situation where this is rarely, if ever, attempted. For example, we highlight the lack of meta-analytic studies in design research. Although comparison (particularly statistical aggregation) is by no means trivial (even using methods such as that proposed) without the elements in the foundational method significant aggregation or comparison attempts are not even possible, severely hampering development in design research. In doing this it is important that the researcher understand the philosophical approaches that define various methods and thus how they are compared. Otherwise incompatible perspectives may be combined leading to erroneous conclusions. In particular the foundational method supports the aggregation of data and does not give direct insight into causal mechanisms. In the causal domain different approaches are needed to establish and explain causal relationships. Thus, although the foundational method may be used to ground causal studies via the generation of baseline data, further development to include casual methods is beyond the scope of this work.

Finally, a more specific limitation of the work reported here is the scope of the comparison study. In the context of the foundational method true validation would require two elements: a systematic comparison across all possible variables and study contexts demonstrating each aspect of the method; a rigorous comparison of the foundational method against all relevant alternative approaches to improving reuse, replication, and comparison. Both of these are significantly beyond the scope of a single study and are likely to only be established reflectively after multiple years of uptake, critique, implementation, and comparison. As such, the comparison study presented in this paper does not claim to validate the method, instead it illustrates the utility of the foundational method and provides an example of how the comparison process can be used to give new insight. 


\section{Conclusions}

This paper outlines the creation of a foundational method for supporting the aggregation of observational studies in the engineering design domain. The method introduces a multi-level approach to capture, coding, and analysis building on pervious works. This comprises multi-stream data capture, combined with a 5 level coding and analysis scheme. Together these promote the wide contextualisation of data and the progressive filtering and focusing of analysis efforts to support standardisation and research specific flexibility.

The foundational method offers several key advantages for improving replication, reuse, and comparison. First, the capture approach formalises the reporting of context and the use of multiple complementary sources in order to produce a broad and robust dataset - allowing for both standardised contextualisation and research specific flexibility. Second, the multi-level coding and analysis strategies combine to promote theory building, standardised contextualisation, comparison, triangulation, and reporting. In particular, the coding and analysis strategies allow successive degrees of detail to be examined whilst maintaining a cohesive structure. Third, there is a significant pragmatic benefit in the reduction of the coding and reporting workload whilst maintaining the contextual grounding and flexibility of the research specific elements. Finally, combining standardisation and flexibility allows effective comparison and triangulation of studies in a standard and transparent manner - key to developing a wider base of research data in the community.

As highlighted in

Table 10 further work is necessary to: identify the significance of various contextual factors and formalise their reporting in design research; develop and validate the links between sample design and the required contextual information; and examine the significance and extent of experimental effects in the engineering design domain. Further, and most critical to this work is the on-going requirement to validate the foundational method in practice. However, as true validation can only come through multiple applications in numerous contexts and by many different researchers, this is beyond the scope of any single study. It is hoped that by providing the basis for such comparisons the foundational method will be validated 
through examination, critique, and adoption by the engineering design research community itself.

\section{Acknowledgements}

The work reported in this paper has been undertaken as part of the EPSRC Innovative Manufacturing Research Centre at the University of Bath (grant reference $\mathrm{GR} / \mathrm{R} 67507 / 0$ ) and has been supported by a number of industrial companies. The authors gratefully acknowledge this and express their thanks for the advice and support of all concerned. We would also like to express our thanks to the reviewers for their insightful input.

\section{References}

Adair, J G. 1984. "The Hawthorne Effect: A Reconsideration of the Methodological Artifact." Journal of Applied Psychology 69 (2): 334-345.

Adelman, L. 1991. "Experiments, Quasi-Experiments, and Case Studies: A Review of Empirical Methods for Evaluating Decision Support Systems." IEEE Transactions on Systems, Man, and Cybernetics 21 (2): 293-301.

Adler, N E, and J M Ostrove. 2006. "Socioeconomic Status and Health: What We Know and What We Don't." Annals of the New York Academy of Sciences 896 (1): 3-15.

Austin, S, J Steele, S Macmillan, P Kirby, and R Spence. 2001. "Mapping the Conceptual Design Activity of Interdisciplinary Teams." Design Studies 22 (3): 211-232.

Ball, L J, and T C Ormerod. 2000. "Putting Ethnography to Work: The Case for a Cognitive Ethnography of Design." International Journal of Human-Computer Studies 53 (1): 147-168.

Balogun, J. 2006. "Managing Change: Steering a Course between Intended Strategies and Unanticipated Outcomes." Long Range Planning 39 (1): 29-49.

Barnes, B R. 2010. "The Hawthorne Effect in Community Trials in Developing Countries." International Journal of Social Research Methodology 13 (4): 357370.

Bedny, G Z, and S R Harris. 2005. "The Systemic-Structural Theory of Activity: Applications to the Study of Human Work." Mind, Culture, and Activity 12 (2): 128-147.

Bergstrom, M, A Ericson, M Larsson, H Nergard, T Larsson, and B Renstrom. 2008. "Needs as a Basis for Design Rationale." Design 2008.

Blandford, A, and S Attfield. 2010. "Interacting with Information." Synthesis Lectures on Human-Centered Informatics 3 (1): 1-99. 
Blessing, L T M, and A Chakrabarti. 2009. DRM, a Design Research Methodology. New York: Springer.

Blessing, L T M, A Chakrabarti, and K M Wallace. 1998. "An Overview of Descriptive Studies in Relation to a General Design Research Methodology." In Designers The Key to Successful Product Development, edited by E Frankenberger, 42-56. Berlin: Springer-Verlag.

Bolton, G E, and A Ockenfels. 2008. Does Laboratory Trading Mirror Behaviour in Real World Markets?: Fair Bargaining and Competitive Bidding on EBay. CESifo.

Brennan, L, S Castro, R C Brownson, J Claus, and C T Orleans. 2011. "Accelerating Evidence Reviews and Broadening Evidence Standards to Identify Effective, Promising, and Emerging Policy and Environmental Strategies for Prevention of Childhood Obesity." Annual Review of Public Health 32: 199-223.

Briggs, R O. 2006. "On Theory-Driven Design and Deployment of Collaboration Systems." International Journal of Human-Computer Studies 64 (7): 573-582.

Carrizosa, K, and S Sheppard. 2000. "The Importance of Learning Styles in Group Design Work." In Frontiers in Education Conference, 2000. FIE 2000. 30th Annual, 1:T2B/12-T2B/17 vol.1.

Cash, P. 2012. "Characterising the Relationship between Practice and LaboratoryBased Studies of Designers for Critical Design Situations." Bath: University of Bath, Dept. of Mechanical Engineering.

Cash, P, B J Hicks, and S J Culley. 2010. "An Information Requirement Strategy for Capturing and Analysing Design Activity and Behaviour." In Design 2010. Design 2010 International Design Conference. Dubrovnik, Croatia.

- - . 2013. "A Comparison of Designer Activity Using Core Design Situations in the Laboratory and Practice." Design Studies 34 (5): 575-611.

Cash, P, B J Hicks, S J Culley, and F Salustri. 2011. "Designer Behaviour and Activity: An Industrial Observation Method." In ICED 11 International Conference on Engineering Design. ICED 11 International Conference on Engineering Design. Copenhagen, Denmark.

Cave, P R, and C E I Noble. 1986. "Engineering Design Data Management." In 1st International Conference on Engineering Management, Theory and Applications. Swansea, UK.

Chenouard, R, P Sebastian, and L Granvilliers. 2007. "Solving an Air Conditioning System Problem in an Embodiment Design Context Using Constraint Satisfaction Techniques." Principles and Practice of Constraint Programming CP 2007: 1832.

Cook, D L. 1962. "The Hawthorne Effect in Educational Research." The Phi Delta Kappan 44 (3): 116-122.

Cooper, R G, S J Edgett, and E J Kleinschmidt. 2002. "Optimizing the Stage-Gate Process: What Best-Practice Companies Do." Research-Technology Management 45 (5): 21-27.

Cross, N. 2007. "Forty Years of Design Research." Design Studies 28 (1): 1-4.

Cunningham, S J. 2005. "Autoethnography: A Tool for Practice and Education." In 6th ACM SIGCHI International Conference on Computer-Human Interaction Making CHI Natural - CHINZ 05, 1. New Zealand. 
D’Astous, P, F Detienne, W Visser, and P N Robillard. 2004. “Changing Our View on Design Evaluation Meetings Methodology: A Study of Software Technical Review Meetings." Design Studies 25 (6): 625-655.

Devereaux, P J, and S Yusuf. 2003. "The Evolution of the Randomized Controlled Trial and Its Role in Evidence-based Decision Making." Journal of Internal Medicine 254 (2): 105-113.

Diaper, G. 1990. "The Hawthorne Effect: A Fresh Examination." Educational Studies; Dorchester-on-Thames 16 (3): 261-267.

Dow, D, and S Ferencikova. 2010. "More than Just National Cultural Distance: Testing New Distance Scales on FDI in Slovakia." International Business Review 19 (1): 46-58.

Dyba, T, and T Dingsoyr. 2008. "Empirical Studies of Agile Software Development: A Systematic Review." Information and Software Technology 50 (9-10): 833-859.

Eisenhardt, K M. 1989. "Building Theories from Case Study Research." Academy of Management Review 14 (4): 532-550.

Falk, A, and J Heckman. 2009. "Lab Experiments Are a Major Source of Knowledge in the Social Sciences." Science 326 (5952): 535-538.

Finger, S, and J R Dixon. 1989a. "A Review of Research in Mechanical Engineering Design. Part I: Descriptive, Prescriptive, and Computer-Based Models of Design Processes." Research in Engineering Design 1 (1): 51-67.

- - . 1989b. "A Review of Research in Mechanical Engineering Design. Part II: Representations, Analysis, and Design for the Life Cycle." Research in Engineering Design 1 (2): 121-137.

Flay, B R, A Biglan, R F Boruch, F G Castro, D Gottfredson, S Kellam, E K Moscicki, S Schinke, J C Valentine, and P Ji. 2005. "Standards of Evidence: Criteria for Efficacy, Effectiveness and Dissemination." Prevention Science 6 (3): 151-175.

Gallivan, M, and M Srite. 2005. "Information Technology and Culture: Identifying Fragmentary and Holistic Perspectives of Culture." Information and Organization 15 (4): 295-338.

Glasgow, R E, and K M Emmons. 2007. "How Can We Increase Translation of Research into Practice? Types of Evidence Needed." Annual Review of Public Health 28 (1): 413-433.

Gorard, S, and T D Cook. 2007. "Where Does Good Evidence Come From?" International Journal of Research \& Method in Education 30 (3): 307-323.

Guzzo, R A, and M W Dickson. 1996. "Teams in Organizations: Recent Research on Performance and Effectiveness." Annual Review of Psychology 47 (1): 307-338.

Haas, R E, F Weber, and K S Panwar. 2000. "Engineering Knowledge Management Current Status and Future Challenges." ICE 2000 International Conference on Concurrent Enterprising.

Hagedorn, J, J Hailpern, and K G Karahalios. 2008. "VCode and VData: Illustrating a New Framework for Supporting the Video Annotation Workflow." In Conference on Advanced Visual Interfaces, 317-321. New York, USA: ACM.

Hales, C. 1987. "Analysis of the Engineering Design Process in an Industrial Context". Cambridge UK: University of Cambridge, Department of Engineering.

Hicks, B J, S J Culley, R D Allen, and G Mullineux. 2002. "A Framework for the Requirements of Capturing, Storing and Reusing Information and Knowledge in 
Engineering Design." International Journal of Information Management 22 (4): 263-280.

Hofstede, G, G J Hofstede, and M Minkov. 2010. Cultures and Organizations:

Software of the Mind, Revised and Expanded 3rd Ed. Vol. 3rd. McGraw-Hill, New York, NY.

Holden, J D. 2001. "Hawthorne Effects and Research into Professional Practice." Journal of Evaluation in Clinical Practice 7 (1): 65-70.

Horvath, I. 2004. "A Treatise on Order in Engineering Design Research." Research in Engineering Design 15 (3): 155-181.

Howard, T J. 2008. "Information Management for Creative Stimuli in Engineering Design." Edited by E Dekoninck. Bath: University of Bath, Departement of Mechanical Engineering.

Howard, T J, S J Culley, and E Dekoninck. 2010. "Reuse of Ideas and Concepts for Creative Stimuli in Engineering Design." Journal of Engineering Design 22 (8): 565-581.

Huet, G, S J Culley, C McMahon, and C Fortin. 2007. "Making Sense of Engineering Design Review Activities." Artificial Intelligence for Engineering Design, Analysis and Manufacturing : Al EDAM 21 (3): 243-266.

Huet, G, C McMahon, F Sellini, S J Culley, and C Fortin. 2007. "Knowladge Loss in Design Reviews." In Advances in Integrated Design and Manufacturing in Mechanical Engineering II, edited by S Tichkiewitch, M Tollenaere, and P Ray, 277-291. Springer.

Jakesch, M, M Zachhuber, H Leder, M Spingler, and C C Carbon. 2011. "ScenarioBased Touching: On the Influence of Top-down Processes on Tactile and Visual Appreciation." Research in Engineering Design 22 (3): 1-10.

Janssen, O, E Van de Vliert, and M West. 2004. "The Bright and Dark Sides of Individual and Group Innovation: A Special Issue Introduction." Journal of Organizational Behavior 25 (2): 129-145.

Kazdin, A E. 1998. Research Design in Clinical Psychology. Needham Heights, MA, USA: Allyn \& Bacon.

Kim, M J, and M L Maher. 2008. "The Impact of Tangible User Interfaces on Spatial Cognition during Collaborative Design." Design Studies 29 (3): 222-253.

King, D W, J Casto, and H Jones. 1994. Communication by Engineers: A Literature Review of Engineers' Information Needs, Seeking Processes, and Use. Washington, DC: Council on Library Resources.

Kitchenham, B A. 1996. "Evaluating Software Engineering Methods and Tool Part 1: The Evaluation Context and Evaluation Methods." ACM SIGSOFT Software Engineering Notes 21 (1): 11-14.

Kitchenham, B A, S L Pfleeger, L M Pickard, P W Jones, D C Hoaglin, K El-Emam, and J Rosenberg. 2002. "Preliminary Guidelines for Empirical Research in Software Engineering." IEEE Transactions on Software Engineering 28 (8): 721-734.

Klein, H K, and M D Myers. 1999. "A Set of Principles for Conducting and Evaluating Interpretive Field Studies in Information Systems." MIS Quarterly: 67-93.

Kogut, B, and H Singh. 1988. "The Effect of National Culture on the Choice of Entry Mode." Journal of International Business Studies 19 (3): 411-432.

Leonard, K, and M C Masatu. 2006. "Outpatient Process Quality Evaluation and the Hawthorne Effect." Social Science \& Medicine 63 (9): 2330-2340. 
Lethbridge, T C, S E Sim, and J Singer. 2005. "Studying Software Engineers: Data Collection Techniques for Software Field Studies." Empirical Software Engineering 10 (3): 311-341.

Levitt, S D, and J A List. 2007. "What Do Laboratory Experiments Measuring Social Preferences Reveal about the Real World?" The Journal of Economic Perspectives 21 (2): 153-174.

Lewis, M, and J Moultrie. 2005. "The Organisational Innovation Laboratory." Creativity and Innovation Management 14 (1): 73-83.

LiveScribe. 2011. "LiveScribe: Never Miss a Word". http://www.livescribe.com/enus/.

Malterud, K. 2001. "Qualitative Research: Standards, Challenges, and Guidelines." The Lancet 358 (9280): 483-488.

ManicTime. 2011. "ManicTime - Time Management Software [Online]". http://www.manictime.com/.

McAlpine, H. 2010. "Improving the Management of Informal Engineering Information through Electronic Logbooks." Edited by S J Culley. Bath: University of Bath, Dept. Mechanical engineering.

McAlpine, H, P Cash, A Storton, and S J Culley. 2011. "A Technology Selection Process for the Optimal Capture of Design Information." In ICORD '11 International Conference on Research into Design. ICORD 11 International Conference on Research into Design. Bangalore, India.

McAlpine, H, B J Hicks, and S J Culley. 2009. "Comparing Formal and Informal Documents: Lessons for More Complete Design Records." In . ICED 09 International Conference on Engineering Design. Stanford University, USA.

McAlpine, H, B J Hicks, G Huet, and S J Culley. 2006. "An Investigation into the Use and Content of the Engineer's Logbook." Design Studies 27 (4): 481-504.

McCandliss, B D, M Kalchman, and P Bryant. 2003. "Design Experiments and Laboratory Approaches to Learning: Steps toward Collaborative Exchange." Educational Researcher 32 (1): 14-16.

Panopto. 2012. "Panopto". www.panopto.com: Panopto Europe Ltd.

Petre, M. 2004. "How Expert Engineering Teams Use Disciplines of Innovation." Design Studies 25 (5): 477-493.

Pickett, K E, and M Pearl. 2001. "Multilevel Analyses of Neighbourhood Socioeconomic Context and Health Outcomes: A Critical Review." Journal of Epidemiology and Community Health 55 (2): 111-122.

Podsakoff, P M, S B MacKenzie, J-Y Lee, and N P Podsakoff. 2003. "Common Method Biases in Behavioural Research: A Critical Review of the Literature and Recommended Remedies." Journal of Applied Psychology 88 (5): 879-903.

Pope, C, and N Mays. 1995. "Reaching the Parts Other Methods Cannot Reach: An Introduction to Qualitative Methods in Health and Health Services Research." BMJ British Medical Journal 311 (6996): 42-45.

Prudhomme, G, F Pourroy, and K Lund. 2007. "An Empirical Study of Engineering Knowledge Dynamics in a Design Situation." Journal of Design Research 6 (3): 333-358.

Puttre, M. 1991. “Product Data Management." Mechanical Engineering 113 (10): 8183. 
Robinson, H, J Segal, and H Sharp. 2007. "Ethnographically-Informed Empirical Studies of Software Practice." Information and Software Technology 49 (6): 540-551.

Robinson, M A. 2010. "An Empirical Analysis of Engineers' Information Behaviours." Journal of the American Society for Information Science and Technology 61 (4): 640-658.

Robson, C. 2002. Real World Research. Vol. 2nd. Chichester: Wiley.

Scaravetti, D, and P Sebastian. 2009. "Design Space Exploration in Embodiment Design: An Application to the Design of Aircraft Air Conditioners." International Journal of Product Development 9 (1): 292-307.

Seale, C. 1999. "Quality in Qualitative Research." Qualitative Inquiry 5 (4): 465-478.

Seale, C, and D Silverman. 1997. "Ensuring Rigour in Qualitative Research." European Journal of Public Health 7 (4): 379-384.

Shalley, C E, and L L Gilson. 2004. "What Leaders Need to Know: A Review of Social and Contextual Factors That Can Foster or Hinder Creativity." The Leadership Quarterly 15 (1): 33-53.

Shavelson, R J, D C Phillips, L Towne, and M J Feuer. 2003. "On the Science of Education Design Studies." Educational Researcher 32 (1): 25-28.

Shenkar, O. 2001. "Cultural Distance Revisited: Towards a More Rigorous Conceptualization and Measurement of Cultural Differences." Journal of International Business Studies 32 (3): 519-535.

Stewart, G L. 2006. "A Meta-Analytic Review of Relationships between Team Design Features and Team Performance." Journal of Management 32 (1): 29-55.

Torlind, P, N Sonalkar, M Bergstrom, E Blanco, B J Hicks, and H McAlpine. 2009. "Lessons Learned and Future Challenges for Design Observatory Research." In . ICED 09 International Conference on Engineering Design. Stanford, CA, USA.

Torlind, P, M Stenius, M Johanson, and P Jeppsson. 1999. "Collaboration Environments for Distributed Engineering Development of a Prototype System." Computer Supported Cooperative Work in Design (CSCWD) 99.

Veldman, J, and A Alblas. 2012. "Managing Design Variety, Process Variety and Engineering Change: A Case Study of Two Capital Good Firms." Research in Engineering Design 23 (4): 269-290.

Visser, W. 2009. “Design: One, but in Different Forms." Design Studies 30 (3): 187223.

Wasiak, J, B J Hicks, L Newnes, A Dong, and L Burrow. 2010. “Understanding Engineering Email: The Development of a Taxonomy for Identifying and Classifying Engineering Work." Research in Engineering Design 21 (1): 43-64.

Wild, P J, S J Culley, C McMahon, M Darlington, and S Liu. 2005. "Starting to Audit Documents in the Engineering Domain." In In-Use, In-Situ: Extending Field Research Methods, edited by P Amaldi, S P Gill, B Fields, and W Wong, 36-40. London: Higher education academy information and computer sciences.

Wild, P J, C McMahon, M Darlington, S Liu, and S J Culley. 2010. "A Diary Study of Information Needs and Document Usage in the Engineering Domain." Design Studies 31 (1): 46-73.

Wildemuth, B M. 1993. "Post-Positivist Research: Two Examples of Methodological Pluralism." The Library Quarterly 63 (4): 450-468. 


\section{Appendix: Summary of the Overall Contextual Factors}

\begin{tabular}{|c|c|c|}
\hline \multicolumn{3}{|c|}{ Company } \\
\hline Focus & Measures & Metric or description \\
\hline \multirow{6}{*}{$\begin{array}{l}\text { Technical } \\
\text { Environment }\end{array}$} & Technical layout & The layout and distribution of equipment \\
\hline & Resources available & The equipment available to the team \\
\hline & Overall layout & Office and site plan \\
\hline & Number of co-workers & Size of working team \\
\hline & Distribution of co-workers & Geographic distribution of team \\
\hline & Types of co-workers & Background and role of team members \\
\hline \multirow[t]{6}{*}{ Social } & Funding/income sources & Source of income for project and company \\
\hline & Market pressures & Competitors and main market forces \\
\hline & Environmental drivers & Environmental and legislative forces \\
\hline & Other pressures & Any other forces affecting the company \\
\hline & $\begin{array}{l}\text { The overall number and } \\
\text { breakdown of employees }\end{array}$ & $\begin{array}{l}\text { Overall } \mathrm{N}^{\circ} \text {, role composition and geographic } \\
\text { distribution of workforce }\end{array}$ \\
\hline & Hypothesis specific employees & $\begin{array}{l}\mathrm{N}^{\circ} \text {, role composition and geographic distribution } \\
\text { of people under investigation }\end{array}$ \\
\hline \multirow[t]{8}{*}{ Cultural } & Main $\operatorname{aim}(\mathrm{s})$ and scope & Company and team aim \\
\hline & Values/mission statement(s) & Company and team priorities and future vision \\
\hline & Expertise & $\begin{array}{l}\text { Composition and distribution of workforce roles } \\
\text { and expertise }\end{array}$ \\
\hline & Company culture & Using Hofsetede et al's (1990) measures \\
\hline & $\begin{array}{l}\text { Focus and level/type of } \\
\text { engineering/design }\end{array}$ & $\begin{array}{l}\text { The complexity and domain of the design work } \\
\text { being undertaken }\end{array}$ \\
\hline & Past projects & $\mathrm{N}^{\circ}$ of related past projects \\
\hline & Significant partners & Sister, parent or subsidiaries \\
\hline & $\begin{array}{l}\text { Significant partners role in } \\
\text { management }\end{array}$ & $\begin{array}{l}\text { Level at which there is contact with and influence } \\
\text { by partners }\end{array}$ \\
\hline \multirow[t]{2}{*}{ Historical } & The turnover of the company & The current size and historical growth \\
\hline & The age of the company & The number of years in the market segment \\
\hline \multicolumn{3}{|c|}{ Participant } \\
\hline Focus & Measures & Metric or description \\
\hline \multirow[t]{3}{*}{$\begin{array}{l}\text { Technical } \\
\text { Environment }\end{array}$} & $\begin{array}{l}\text { Specific technical features of } \\
\text { the participants work station }\end{array}$ & $\begin{array}{l}\text { Operating system and specialist software/tools } \\
\text { available }\end{array}$ \\
\hline & $\begin{array}{l}\text { Distribution of time across } \\
\text { work areas }\end{array}$ & $\begin{array}{l}\text { Nominal time working in office, workshop, home } \\
\text { etc. }\end{array}$ \\
\hline & Use of resources & $\begin{array}{l}\text { Resources available to the participant e.g. } \\
\text { whiteboard, notepad, phone, bookshelves etc. }\end{array}$ \\
\hline \multirow[t]{2}{*}{ Social } & Socioeconomic status & $\begin{array}{l}\text { Age, role, highest level of education, gross } \\
\text { individual annual income, level of property } \\
\text { ownership }\end{array}$ \\
\hline & $\begin{array}{l}\text { Area-based measure of } \\
\text { socioeconomic status }\end{array}$ & $\begin{array}{l}\text { Using e.g. ACORN www.caci.co.uk/acorn- } \\
\text { classification.aspx }\end{array}$ \\
\hline \multirow[t]{2}{*}{ Cultural } & $\begin{array}{l}\text { Nationality and national } \\
\text { heritage }\end{array}$ & $\begin{array}{l}\text { Current nationality, previous nationalities or time } \\
\text { in other countries }\end{array}$ \\
\hline & Cultural distance measures & Using Hofsetede et al's (2010) measures \\
\hline Historical & $\begin{array}{l}\text { Formal education: subjects and } \\
\text { grades and focus }\end{array}$ & $\begin{array}{l}\text { Subjects and grades, focus of any larger projects } \\
\text { e.g. Masters thesis }\end{array}$ \\
\hline
\end{tabular}




\begin{tabular}{|l|l|l|}
\hline \hline & Professional qualifications & Subjects and levels (where relevant) \\
\cline { 2 - 3 } & $\begin{array}{l}\text { Professional experience over } \\
\text { six months }\end{array}$ & Role, duration, description of company \\
\hline & $\begin{array}{l}\text { Development within the } \\
\text { current professional } \\
\text { framework }\end{array}$ & $\begin{array}{l}\text { Participation in development schemes in the } \\
\text { company e.g. leader development or technical } \\
\text { training }\end{array}$ \\
\hline
\end{tabular}

\section{Appendix: Code Definitions}

\begin{tabular}{|c|c|c|}
\hline Group & Code & Definition \\
\hline \multirow[t]{6}{*}{ Situation } & Individual & No real time interaction with any other individual or group \\
\hline & Group & Real time interaction with one or more other individuals \\
\hline & Synchronous & No delays between communications \\
\hline & Asynchronous & $\begin{array}{l}\text { Significant delays (longer than a few seconds) between } \\
\text { communications }\end{array}$ \\
\hline & Co-located & Working in the same location at the time of an interaction \\
\hline & Distributed & Working in different locations at the time of an interaction \\
\hline Environment & Location & The specific location of the participant in their main work site \\
\hline \multirow[t]{4}{*}{ Focus } & $\begin{array}{l}\text { Design process } \\
\text { stage }\end{array}$ & $\begin{array}{l}\text { The stage at which an interaction is taking place within the } \\
\text { associated project - see Hales (1987) for stage definitions }\end{array}$ \\
\hline & People & $\begin{array}{l}\text { The subject of an interaction includes: personnel, personal, } \\
\text { managing people, customers }\end{array}$ \\
\hline & Product & $\begin{array}{l}\text { The subject of an interaction includes: prototypes, design } \\
\text { documents, project management }\end{array}$ \\
\hline & Process & $\begin{array}{l}\text { The subject of an interaction includes: resources/time allocation, } \\
\text { scheduling, stage gate management }\end{array}$ \\
\hline \multirow{8}{*}{$\begin{array}{l}\text { Problem } \\
\text { solving }\end{array}$} & Goal setting & Identifying where the design is and where it needs progressing to \\
\hline & Constraining & Imposing boundaries with requirements and desirables \\
\hline & Exploring & Discussing possibilities and ideas invoking suggestions \\
\hline & Solving & Involves searching, gathering, creating, developing solutions \\
\hline & Evaluating & Judging the quality, value and importance of something \\
\hline & $\begin{array}{l}\text { Decision } \\
\text { making }\end{array}$ & $\begin{array}{l}\text { Considering key factors from evaluation and possible } \\
\text { compromises to form decisions }\end{array}$ \\
\hline & Reflection & $\begin{array}{l}\text { Reflecting upon a design decision or process already adopted or } \\
\text { occurred }\end{array}$ \\
\hline & Debating & Discussing opposing views \\
\hline \multirow[t]{8}{*}{$\begin{array}{l}\text { Information } \\
\text { exchange }\end{array}$} & $\begin{array}{l}\text { Recognising } \\
\text { need }\end{array}$ & Recognising a problem or deficit \\
\hline & Seeking & Finding information \\
\hline & Requesting & Direct requests to another party to provide information \\
\hline & Interpretation & Assigning meaning or value to information \\
\hline & Validation & Checking the authenticity or value of information \\
\hline & Informing & Using information to inform one or more people \\
\hline & Clarifying & $\begin{array}{l}\text { Using information specifically to resolve issues or clarity } \\
\text { problems }\end{array}$ \\
\hline & Confirming & $\begin{array}{l}\text { Using information specifically to affirm or confirm a issue or } \\
\text { point }\end{array}$ \\
\hline $\begin{array}{l}\text { Management } \\
\text { exchange }\end{array}$ & Managing & $\begin{array}{l}\text { Specifically arranging, directing or instructing with regards to } \\
\text { people, product or process }\end{array}$ \\
\hline \multirow[t]{3}{*}{ Audiovisual } & Audio only & Only using audio input or output \\
\hline & Visual only & Only using visual inputs or outputs \\
\hline & Audiovisual & Using both audio and visual inputs or outputs \\
\hline Documentation & Formal & $\begin{array}{l}\text { Provides a specific context and measure with a structure or a } \\
\text { focus such that individuals exposed to it may infer the same } \\
\text { knowledge from it (Hicks et al. 2002) }\end{array}$ \\
\hline
\end{tabular}




\begin{tabular}{|l|l|l|}
\hline & Informal & $\begin{array}{l}\text { This encompasses any unstructured information (Hicks et al. } \\
\text { 2002) }\end{array}$ \\
\hline Physical & Environment & Physical objects not directly related to the design \\
\cline { 2 - 3 } & Tools & Design tools used with respect to the design (Schon 1984) \\
\cline { 2 - 3 } & $\begin{array}{l}\text { Design } \\
\text { representations }\end{array}$ & $\begin{array}{l}\text { Objects related to the specific design under discussion - } \\
\text { prototypes, visualisations, mock-ups etc }\end{array}$ \\
\hline \hline \multirow{2}{*}{$\begin{array}{l}\text { Type of } \\
\text { exchange }\end{array}$} & Opinion & $\begin{array}{l}\text { Giving or receiving opinions: includes evaluation, analysis, } \\
\text { expression of feeling or wish }\end{array}$ \\
\hline & Orientation & $\begin{array}{l}\text { Giving or receiving orientation or scene setting: includes } \\
\text { information, repetition, confirmation }\end{array}$ \\
\hline Understanding & Suggestion & $\begin{array}{l}\text { Giving or receiving direction or proposed possibilities: includes } \\
\text { direction, possible modes of action }\end{array}$ \\
\hline Personal & $\begin{array}{l}\text { Antagonism/ } \\
\text { solidarity }\end{array}$ & $\begin{array}{l}\text { The participant shows passive acceptance/rejection, } \\
\text { understands, concurs, complies/formality, withholds resources }\end{array}$ \\
\cline { 2 - 3 } & $\begin{array}{l}\text { Tension/ } \\
\text { tension release } \\
\text { status, gives help or rewards others/asserts or defends self }\end{array}$ \\
\hline
\end{tabular}

